\title{
Systematic design of an optimal control system for the SHARON-Anammox process
}

\author{
Valverde Perez, Borja; Mauricio Iglesias, Miguel; Sin, Gürkan
}

Published in:

Journal of Process Control

Link to article, DOI:

10.1016/j.jprocont.2015.12.009

Publication date:

2016

Document Version

Peer reviewed version

Link back to DTU Orbit

Citation (APA):

Valverde Perez, B., Mauricio Iglesias, M., \& Sin, G. (2016). Systematic design of an optimal control system for the SHARON-Anammox process. Journal of Process Control, 39, 1-10.

https://doi.org/10.1016/j.jprocont.2015.12.009

\section{General rights}

Copyright and moral rights for the publications made accessible in the public portal are retained by the authors and/or other copyright owners and it is a condition of accessing publications that users recognise and abide by the legal requirements associated with these rights.

- Users may download and print one copy of any publication from the public portal for the purpose of private study or research.

- You may not further distribute the material or use it for any profit-making activity or commercial gain

- You may freely distribute the URL identifying the publication in the public portal 


\title{
Systematic design of an optimal control system for the SHARON-Anammox process
}

Borja Valverde-Pérez ${ }^{1,2}$, Miguel Mauricio-Iglesiass ${ }^{1,3}$, Gürkan Sin ${ }^{1 *}$.

${ }^{1}$ CAPEC-PROCESS, Department of Chemical and Biochemical Engineering, Technical University of Denmark Søltofts Plads, Building 229, DK - 2800, Kgs. Lyngby, Denmark

${ }^{2}$ Urban Water Technology, Department of Environmental Engineering, Technical University of Denmark, Miljøvej, Building 115, DK - 2800, Kgs. Lyngby, Denmark

${ }^{3}$ Department of Chemical Engineering, Universidade de Santiago de Compostela, 15782, Santiago de Compostela, Spain

*Corresponding author: gsi@kt.dtu.dk

\begin{abstract}
A systematic design of an optimal control structure for the SHARON-Anammox nitrogen removal process is studied. The methodology incorporates two novel features to assess the controllability of the design variables candidate for the regulatory control layer: (i) $H_{\infty}$ control method, which formulates the control problem as a mathematical optimization problem, and (ii) close-loop disturbance gain (CLDG) plots. It is shown that the methodology is especially appropriate for bioreactors. The solution of the mixed sensitivity stacked $H_{\infty}$ control problem ranked the combinations of controlled variables $(\mathrm{CVs})$. The best candidates to $\mathrm{CVs}$ were paired with the manipulated variables using the relative gain array. The proposed control structure was further analyzed and verified for disturbance rejection using the CLDG plots. The optimal pairing of CVs with the actuators ( $\mathrm{k}_{\mathrm{L}} \mathrm{a}$ and acid/base addition) is found to be dissolved oxygen (DO) and $\mathrm{pH}$ in the SHARON reactor. Furthermore, to relate the controller actions to process operation objective, nitrogen removal efficiency, two cascade control systems are designed. The first cascade loop controls TNN/TAN ratio in the influent to the Anammox reactor by adjusting the set point for DO in the regulatory layer, while the second cascade loop controls the nitrogen removal efficiency (i.e. effluent TNN and TAN) by adjusting the TNN/TAN ratio at the effluent of the SHARON reactor. The control system is evaluated and benchmarked using a set of realistic dynamic scenario simulations, demonstrating that the different control strategies successfully maintain stable and high nitrogen removal efficiency. The nested cascade control structure shows the best performance, removing up to $95 \%$ of the influent ammonia. Both the control design methodology and the resulting optimal control structures are expected to contribute to stable operation and control of these emerging nitrogen removal technologies.
\end{abstract}

Keywords: Control design; H-infinity; Anammox; autotrophic nitrogen removal; disturbance analysis; process modeling

\section{ABBREVIATIONS}

AOB

AnAOB

BSM2

CANR
Ammonia oxidizing bacteria Anaerobic ammonia oxidizing bacteria Benchmark simulation model 2 Completely
removal
MV Manipulated variable

PI Proportional-Integral

RGA Relative gain array

SBR Sequencing batch reactor 


$\begin{array}{llll}\text { CLDG } & \text { Close loop disturbance gain } & \text { SHARON } & \begin{array}{l}\text { Single reactor system for High } \\ \text { activity ammonium removal over nitrite }\end{array} \\ \text { COD } & \text { Chemical oxygen demand } & \text { SRT } & \text { Solid retention time } \\ \text { CSTR } & \text { Continuous stirred tank reactor } & \text { TAN } & \text { Total ammonia nitrogen } \\ \text { CV } & \text { Controlled variable } & \text { TIC } & \text { Total inorganic carbon } \\ \text { DO } & \text { Dissolved oxygen } & \text { TNN } & \text { Total nitrite nitrogen } \\ \text { IAE } & \text { Integral absolute error } & \text { TV } & \text { Total variation } \\ \text { IMC } & \text { Internal model control } & \text { WWTP } & \text { Wastewater treatment plant }\end{array}$

\section{INTRODUCTION}

Complete autotrophic nitrogen removal (CANR) is especially suitable for wastewaters containing high concentrations of nitrogen and low organic carbon loads, such as sludge digestion liquor, landfill leachate or especial industrial wastewaters [1]. Autotrophic nitrogen removal is a sequence of two different processes carried out by two different microbial groups. In a first step (Eq. (1)), named partial nitritation, ammonium $\left(\mathrm{NH}_{4}^{+}\right)$is partially converted to nitrite $\left(\mathrm{NO}_{2}^{-}\right)$by ammonia oxidizing bacteria (AOB). Then, anaerobic ammonia oxidizing bacteria (AnAOB) oxidize the remaining $\mathrm{NH}_{4}^{+}$using the produced $\mathrm{NO}_{2}^{-}$as electron acceptor, thereby producing nitrogen gas $\left(\mathrm{N}_{2}\right)$ [2]. This process (Eq. (2)) is referred to as anaerobic ammonia oxidation or Anammox process.

$$
\begin{aligned}
& \mathrm{NH}_{4}^{+}+1.38 \mathrm{O}_{2}^{-}+0.09 \mathrm{CO}_{2} \rightarrow 0.018 \mathrm{C}_{5} \mathrm{H}_{7} \mathrm{NO}_{2}+0.98 \mathrm{NO}_{2}^{-}+1.98 \mathrm{H}^{+}+0.95 \mathrm{H}_{2} \mathrm{O} \\
& \mathrm{NH}_{4}^{+}+1.31 \mathrm{NO}_{2}^{-}+0.066 \mathrm{HCO}_{3}^{-}+0.13 \mathrm{H}^{+} \\
& \rightarrow 1.02 \mathrm{~N}_{2}+0.26 \mathrm{NO}_{3}^{-}+0.066 \mathrm{CH}_{2} \mathrm{O}_{0.5} \mathrm{~N}_{0.15}+2.03 \mathrm{H}_{2} \mathrm{O}
\end{aligned}
$$

CANR presents some advantages compared with conventional nitrification-denitrification: i) there is no need of external carbon sources when organic carbon is not present in the influent; ii) lower aeration costs (up to 63\% cost reduction [3]); and iii) sludge production is comparably low ( $90 \%$ sludge reduction [4]). However, due to the low growth rate of the Anammox bacteria, reactors have to be equipped with retention systems, such as membranes or carriers. This process can be implemented in two possible configurations: (i) as a sequence of two bioreactors so called two stages systems and (ii) as a single biofilm reactor also called one stage system. The control of one stage CANR technology operated as a continuous system and as a sequencing batch reactor (SBR) has been previously addressed [5-6]. In this study we focus on the synthesis of a control structure for the two-stage SHARON-Anammox process.

Other bacterial groups present in CANR systems limit the range of operating conditions possible in the process. For instance, nitrite oxidizing bacteria (NOB) compete with AnAOB for nitrite and with AOB for oxygen. As NOB can only grow under aerobic conditions, they have to be washed out from the SHARON reactor by operating comparably high temperatures $\left(30^{\circ} \mathrm{C}\right)$ and short solid retention times (SRT) of 1 day approximately [7]. NOB can be also removed by operating the reactor at comparably low oxygen concentrations, thus inhibiting their activity [8]. Finally, NOB activity can be hindered by regulating $\mathrm{pH}$, as these bacteria are more sensitive than $\mathrm{AOB}$ to free ammonia inhibition [9]. Heterotrophic bacteria are also present in these systems, growing on the 
bioavailable chemical oxygen demand (COD) present in the influent and on the decay products from biomass [10]. Heterotrophic activity impacts on nitrogen removal by competing for oxygen with AOB and by denitrifying the nitrate or nitrite produced by autotrophs [11]. Heterotrophs cannot be washed out from the system due to their faster growth rates in comparison with AOB under aerobic conditions. Hence, it is important to develop control systems able to keep the desirable operation of the CANR system when the COD load is comparably high, thereby compromising nitrogen removal [5].

Usually it is assumed that by controlling the partial nitratiation is enough to achieve a high nitrogen removal. Therefore, previous research has done an effort to control the ratio between nitrite and ammonia (TNN/TAN ratio) in the effluent of the SHARON reactor [12-15]. In that work, focus is made on regulating the SHARON reactor in order to provide an optimal influent for the Anammox reactor, independently of the actual performance of the downstream reactor. However, it has been reported that operational conditions in the Anammox reactor, as $\mathrm{pH}$, can also limit the nitrogen removal [16]. By applying the proposed control strategies, the operation conditions of the SHARON reactor may not change even the performance of the Anammox reactor does (e.g. performance change due to bacterial community change). Most of the full scale implementations of CANR have available the different online measurements needed to implement these control strategies. However, most of the implemented control strategies focus on keeping the desirable $\mathrm{pH}$ or dissolve oxygen (DO) level while ammonia, nitrite and nitrate are used for monitoring rather than for control purposes [17].

We consider that, given the available monitoring systems, it will be possible to improve the controllability of the two-stage system by operating the SHARON reactor taking into account the process performance of the downstream Anammox. Therefore, the goal of this contribution is to present a stepwise systematic assessment and design of a control system for the CANR process in two reactor configuration. To this end, we use a plantwide control procedure [18], which has been previously found as suitable systematic approach for control structure design in wastewater treatment plants [19]. An important challenge in the design of control structures for wastewater treatment units, and generally for bioreactors, is the scarcity of control degrees of freedom (i.e. actuators). Since the number of potential controlled variables is usually large, the pairing with the actuators is not straightforward. A possible approach is to address only the regulation of the process with the variables that are best controlled by the actuators (e.g. control DO concentration by manipulating aeration), without taking into account the interactions between loops when there is more than one controlled variable. On the other hand, it is tempting to control variables that relate directly to the performance of the process (e.g. in this case the nitrogen species concentration) in order to achieve an optimal operation. However, such variables may be difficult to control by the available actuators. More systematic approaches have been proposed to tackle the pairing of controlled and manipulated variables in the regulatory layer, like the use of the relative gain array [20] or sensitivity analysis [21]. In contrast, we apply for the first time controllability indicators based the use of $H_{\infty}$ design and closed loop disturbance gain (CLDG) plots for the selection controlled variables (CVs) in bioreactors. The methodology combines two important paradigms of classical control i) set-point tracking: highest sensitivity of controlled variable to manipulated 
variable while considering the loop interactions; and ii) disturbance rejection: lowest sensitivity of controlled variable to disturbances. The use of these tools is integrated in a plantwide control procedure and specifically adapted to the design of control structure in wastewater treatment plants (WWTPs).

The main parts of this paper are: i) a brief description of the model and the scenario used as case study; ii) presentation of the adapted methodology for control structure design for wastewater treatment processes; and iii) application of the methodology to design an optimal control structure for the SHARON-Anammox system, iv) evaluation.

\section{MATERIALS AND METHODS}

\subsection{System description}

The case study used in this work is adapted from an experimental description previously reported [22]. The SHARON reactor is a continuous stirred tank reactor (CSTR) with a volume of $4 \mathrm{~L}$ and a hydraulic retention time (HRT) of 1 day. The nominal levels of DO concentration and $\mathrm{pH}$ are optimized through scenario-based simulations with respect to the objectives of the process in relation with nitrogen removal, while the temperature is set at $35{ }^{\circ} \mathrm{C}$. Influent composition is $700 \mathrm{~N}$ $\mathrm{g} \mathrm{m}^{-3}$ of total nitrogen from ammonia (TAN), $600 \mathrm{C}-\mathrm{g} \mathrm{m}^{-3}$ of bicarbonate (equimolar to TAN) and 100 COD-g $\mathrm{m}^{-3}$ of readily biodegradable organic matter $\left(\mathrm{S}_{\mathrm{s}}\right)$, while the influent $\mathrm{pH}$ is 8 . The Anammox reactor is modeled as a $20 \mathrm{~L}$ CSTR with a membrane as solid retention system to allow AnAOB growth. Temperature in this reactor is $30^{\circ} \mathrm{C}$ and $\mathrm{pH} 8$.

\subsection{Reactor modelling:}

The model used to describe the process is adapted from previous research in the field [7]. Both compartments were modeled as CSTRs. Assuming that the reactor hold-up and all the flows have the same constant density, the global and individual mass balances are:

$\frac{d V}{d t}=\sum_{n=1}^{i} F_{\text {in }}^{i}-F_{\text {out }}$

$\frac{d\left(V \cdot C_{j}\right)}{d t}=F_{\text {in }} \cdot C_{j, \text { in }}-F_{\text {out }} \cdot C_{j}+k_{L} a_{j} \cdot\left(C_{j}^{*}-C_{j}\right) \cdot V+r_{j} \cdot V$

where $F$ stands for the volumetric flows, $C$ for the concentrations, $r$ for the reaction rates and $V$ for the volume of the reactor. The subscripts IN and ouT stand for inflow and outflow respectively, $i$ for the different influents to the reactor, $j$ for the different components and superscript $*$ for the concentration that would be in equilibrium with the gas phase. The considered soluble compounds are total nitrogen from ammonia ( $\mathrm{TAN}=\mathrm{NH}_{4}{ }^{+}+\mathrm{NH}_{3}$ ), total nitrogen from nitrite $\left(\mathrm{TNN}=\mathrm{HNO}_{2}+\mathrm{NO}_{2}{ }^{-}\right)$, total inorganic carbon $\left(\mathrm{TIC}=\mathrm{CO}_{2}+\mathrm{HCO}_{3}{ }^{-}+\mathrm{CO}_{3}{ }^{2-}\right)$, nitrate, nitrogen, oxygen, readily biodegradable organic matter $\left(S_{s}\right)$ and charge not involved in biological processes $(Z)$, while the particulate ones are ammonia oxidizing bacteria $\left(\mathrm{X}_{\mathrm{AOB}}\right)$, nitrite oxidizing bacteria $\left(\mathrm{X}_{\mathrm{NOB}}\right)$, anaerobic ammonia oxidizing bacteria $\left(\mathrm{X}_{\mathrm{AnAOB}}\right)$, heterotrophic bacteria $\left(\mathrm{X}_{\mathrm{HB}}\right)$, slow biodegradable 
organic matter $\left(\mathrm{X}_{\mathrm{S}}\right)$ and inert particulate matter $\left(\mathrm{X}_{\mathrm{I}}\right)$. The individual mass balances are set for the lumped compounds as well as $\mathrm{O}_{2}, \mathrm{NO}_{3}{ }^{-}, \mathrm{S}_{\mathrm{s}}, \mathrm{Z}$ and particulate compounds. The individual mass balance is modified when particulate compounds are modeled in the Anammox reactor, taking into account the retention system (e.g. membrane separation):

$\frac{d\left(V \cdot X_{j}\right)}{d t}=F_{\text {in }} \cdot X_{j, \text { in }}-F_{\text {out }} \cdot(1-R) \cdot X_{j}+r_{j} \cdot V$

where $R$ is the fraction of sludge retained in the Annamox reactor.

Ten different biological processes are included in both reactors models. The stoichiometric matrix and the expressions of microbial growth and decay rates of all bacteria groups for both reactors have been taken from Vangsgaard et al., (2012) [23] and are described in detail in the supplementary material (SI-1).

Microbial activity affects to the $\mathrm{pH}$ since reactions imply a production (partial nitritation, Eq. (1)) or consumption (Anammox process, Eq.(2)) of protons. At the same time, $\mathrm{pH}$ has two different effects on the bacterial activity. On one hand, $\mathrm{pH}$ impacts on the speciation and as a consequence the concentration of $\mathrm{NH}_{3}$ and $\mathrm{HNO}_{2}$. These neutral species, rather than the ionized form, are the real substrates or inhibitors of autotrophic bacteria [9,24]. On the other hand, bacterial activity is affected by $\mathrm{pH}$. In order to account with the second effect, maximum microbial growth rate of the different bacterial groups is modeled as suggested by van Hulle et al. (2007) [25]. The pH is determined solving the corresponding mass balances, equilibrium equations and charge balance. The resulted system of 13 nonlinear equations is solved by a multidimensional Newton-Raphson method adapted from Vangsgaard et al. (2013) [26] also shown in the supplementary material.

Sensors and actuators are modelled as ideal (immediate response with perfect accuracy) given the slow response of the system.

The model was implemented and solved in Simulink environment in MATLAB R2009b (The MathWorks, Natick, MA). Further details about the models and their implementation are provided in the supplementary information (SI-1). Additionally, Matlab control toolbox algorithms were used to perform frequency response analysis for the CLDG plots.

\section{CONTROL DESIGN PROCEDURE}

The control structure design is based on a modification of the plantwide control procedure proposed by Larson and Skogestad (2000) [18] consisting of a top-down analysis and bottom-up design. The procedure is modified to include two novel features to solve the optimal regulatory control layer problem: i) $\mathrm{H}_{\infty}$ control method for screening and ranking controlled variable candidates; and ii) CLDG to assess the optimal pairing of controlled variables for disturbance rejection.

\subsection{Step 1: Goal definition and process optimization}

The top-down analysis starts by defining the goal(s) of the process. As a second step, the process is optimized through scenario simulations. To this end, we considered as criterion of optimal 
operation to produce an effluent TNN/TAN ratio of 1.3 in the SHARON reactor, yielding to the highest nitrogen removal based on the process stoichiometry (Eq. 1 and 2). DO and pH were the operation conditions chosen to optimize the process performance. Bounds considered were between 6.8 and 7.8 for $\mathrm{pH}$, and between $0 \mathrm{~g} \mathrm{~m}^{-3}$ and $0.5 \mathrm{~g} \mathrm{~m}^{-3}$ for DO. Simulations were run for each pair of values of oxygen and $\mathrm{pH}$ until the steady state was reached. In particular, the ratio between TNN and TAN was recorded.

\subsection{Step 2: Degrees of freedom analysis}

The set of variables that can be measured are identified, as well as the set of actuators that can be used to dynamically manipulate the operation (analysis of control degrees of freedom). These two sets identify the candidates to controlled variables (CVs) and manipulated variables (MVs) respectively.

\subsection{Step 3: Ranking of controlled variables based on controllability criteria using $H_{\infty}$ analysis}

The selection of CVs is done by adapting a procedure presented by Jahanshahi et al. (2012) [27] which, for each possible combination of CVs, solves a mixed-sensitivity stacked $H_{\infty}$ control problem [28]. The basic idea of the procedure is to specify a desired loop shape for one or several closed-loop functions and then find the controller that minimizes the $H_{\infty}$ norm (the maximum singular value of the closed-loop functions for the whole bandwidth considered). Hence, the $H_{\infty}$ norm is defined as:

$\|F(G, C)\|_{\infty}=\max _{\omega} \bar{\sigma}(F(G, C)(j \omega))$

where $\bar{\sigma}$ indicates the maximum singular values and $F$ is any closed-loop transfer function depending on the plant $(G)$ and the controller $(C)$. The sensitivity $(S)$ and complementary sensitivity function $(T)$ are defined as:

$S=(I+C S)^{-1}$

$T=C S(I+C S)^{-1}$

Hence, the mixed sensitivity stacked problem consists on finding the controller that minimizes the $\mathrm{H}_{\infty}$ norm, formulated as:

$\min _{C}\|F(G, C)\|_{\infty}$ where $F \triangleq\left(\begin{array}{c}W_{U} C S \\ W_{T} T \\ W_{P} S\end{array}\right)$

where $W_{i}$ are the matrices of the weighting functions for each of the closed-loop transfer functions, namely i) $C S$, which must be bounded to penalize large inputs, ii) $T$ which must be bounded to ensure robustness and low sensitivity to noise, and iii) $S$ which must be bounded for performance (disturbance rejection and set point tracking). The weighting functions are usually defined in order to shape appropriately each of the closed-loop transfer functions, e.g. a low-pass filter for the 
elements of $W_{p}$ will force $S$ to be small over the same low frequencies and leads to good disturbance rejection [28].

The solution to this optimization problem leads to a stabilizing controller, $C$, which satisfies the following inequalities:

$\bar{\sigma}(C S(j \omega)) \leq \gamma \underline{\sigma}\left(W_{U}^{-1}(j \omega)\right)$

$\bar{\sigma}(T(j \omega)) \leq \gamma \underline{\sigma}\left(W_{T}^{-1}(j \omega)\right)$

$\bar{\sigma}(S(j \omega)) \leq \gamma \underline{\sigma}\left(W_{P}^{-1}(j \omega)\right)$

Hence, $\gamma$ is a bound of the peaks of the closed-loop transfer functions (strictly, of the maximum singular values) and can be seen as a measure of controllability, i.e. a low $\gamma$ will indicate good controllability and is a criterion for CV selection. The controller resulting from this optimization is in general a state controller with the same number of states as the plant.

3.4 Step 4. Pairing of the controlled variables with the manipulated variables using the relative gain array

The relative gain array (RGA) is calculated as follows:

$R G A=G \otimes\left(G^{-1}\right)^{T}$

where $G$ is the plant transfer function and $\otimes$ denotes the element by element multiplication.

The RGA matrix represents the influence of the other control loops on a certain output. If the value of a $\lambda_{\mathrm{ij}}$, which is the element " $\mathrm{ij}$ " of the RGA, is close to one and the other RGA elements of the same row are close to zero, the output " $\mathrm{i}$ "' in the pair " $\mathrm{ij}$ "' is not affected by the other control loops [29].

The RGA should be calculated for the best candidates for CVs. If the RGA reveals high interaction between the control loops the next candidates for CVs according to the ranking from step 3 should be analysed until a suitable pairing is found.

3.5 Step 5. Evaluation of the control structure based on disturbance rejection using closed-loop disturbance gain plots

The disturbance effects on the candidates to CVs paired with the different MVs are characterized by the CLDG defined as:

$C L D G \equiv \Delta=\operatorname{diag}(G) G^{-1} G_{d}$

where $G$ is the plant transfer function, $\operatorname{diag}(G)$ is the matrix consisting of diagonal elements of $\mathrm{G}$ and $G_{d}$ is the disturbance transfer function. The magnitude of the CLDG element $\delta_{i j}$ indicates the effect of the ith disturbance on the jth controlled variable at any given frequency. If the variables are 
suitably scaled, a $\delta_{i j}$ lower than 1 indicates that the disturbance will not lead the controlled variable to an unacceptable offset [30].

The CLDG plots should be evaluated for the candidates for CVs found as optimal from steps 3 and 4. This step serves as a verification of the pairing given by the RGA and as an assessment of the impact of the disturbances on the system. In a number of cases, in particular downstream processes, the disturbances can be well characterized and this information can be used by determining the CLDG elements. If the disturbances lead the CVs to unacceptable offset the next candidates for CVs according to the ranking from step 3 should be analysed until a suitable pairing is found according to both RGA and CLDG plots.

\subsection{Step 6. Controller tuning}

Once the pairing of controlled and manipulated variables is done, all controllers are tuned using the internal model control (IMC) guidelines [29]. All the controllers used in this work are proportionalintegral controllers (PI).

\subsection{Step 7. Supervisory layer design}

The regulatory control layer has been designed to keep stable operation under dynamic conditions. However, if the objectives of the operation are not properly represented by the CVs, a supervisory layer can be needed to better relate the process objectives and the CVs. The supervisory layer can be done as cascaded linear controllers, model predictive control, etc.

\subsection{Step 8. Evaluation}

Finally, the control structures are assessed through dynamic simulations. In this work, the three proposed control structures were tested for disturbance rejection using a simulated influent used for benchmarking. The selected influent is the benchmark simulating model 2 (BSM2 [31]) outflow of the anaerobic digester for 30 days (Fig. 1). The influent accounts with diurnal and weekly variations in flow rate and rainfall.

$<$ Fig.1 $>$

Commonly, two types of performance indicators can be determined:

i) the performance on the error (e.g. the integral of absolute error - IAE, Eq. (13)), which measures the offset of the controlled variables,

$$
I A E=\int_{0}^{\infty}|e(t)| d t
$$

ii) the penalty on moves (e.g. the total variance (TV, Eq. (14)) of manipulated variables, which represents the variations in control action needed to reject the disturbance.

$$
T V=\sum_{i=1}^{\infty}\left|u_{i+1}-u_{i}\right|
$$


In addition, performance and economic indicators can be included in order to better compare the different control strategies. In this case study we use nitrogen removal efficiency as performance indicator, while as economic indicators we use the aeration energy demand [32] and the chemical dosing needed to control $\mathrm{pH}$.

The different steps of the proposed methodology are summarized in Table 1.

$<$ Table1 $>$

\section{APPLICATION OF THE METHODOLGY}

\subsection{Step 1: Goal definition and process optimization}

The SHARON-Anammox reactor sequence is used in the treatment plant to remove nitrogen from high strength waste waters with low content on organic carbon. Therefore, the goal of the control system is to achieve a high and stable nitrogen removal.

Based on stoichiometry (Eq. (1) and (2)), nitrogen removal is optimal when the effluent of the SHARON reactor has TNN/TAN ratio of 1.3. Accordingly, the optimal operation conditions in the SHARON reactor are determined mapping the effect of $\mathrm{pH}$ and $\mathrm{DO}$ on the performance of the reactor (Fig. 2). The TNN/TAN ratio shows an optimal point at $\mathrm{pH} 7.3$ and a monotonous increase with DO which stabilizes asymptotically for excess of oxygen (Fig. 2). Therefore, in order to operate at minimum DO, and as a consequence decrease the needs of aeration, the selected operating conditions are $\mathrm{pH}=7.3$ and $\mathrm{DO}=0.2 \mathrm{~g} \mathrm{~m}^{-3}$, corresponding to a ratio TNN/TAN of 1.3. Found values are in close agreement with the set points reported by Volcke et al. (2007) [3]. They chose as optimal $\mathrm{pH} 7.23$, based on the maximum microbial growth rate dependency on $\mathrm{pH}$ for autotrophic bacteria [25], while the oxygen set point was initially set to $1.5 \mathrm{~g} \mathrm{~m}^{-3}$. However, when the oxygen set point was controlled by the master control loop based on measurements of TNN/TAN in the SHARON effluent, the oxygen level was drastically lowered to a value close to $0.1 \mathrm{~g} \mathrm{~m}^{-3}$.

$<$ Figure $2>$

\subsection{Step 2: Degrees of freedom analysis}

As stated earlier, the goal of the SHARON reactor is to provide a stable feed for the Anammox reactor with a molar ratio TNN/TAN of 1.3. This objective can be achieved using the molar ratio TNN/TAN as a CV. However, in order to keep a stable operation, other variables have to be controlled, as DO, pH or HRT. There are three available actuators or degrees of freedom in the SHARON reactor: i) the air supply, modelled through the $\mathrm{k}_{\mathrm{L}} \mathrm{a}$; ii) the acid $\left(98 \% \mathrm{H}_{2} \mathrm{SO}_{4}\right)$ or base $(50 \% \mathrm{NaOH})$ flows into the reactor; and c) the effluent flow rate. If the SHARON reactor is directly fed from a digester, the influent flow rate is a disturbance and therefore the level has to be controlled using the outflow as a MV. As a consequence, there are only two degrees of freedom left: aeration and the acid or base flow. In case of the Anammox reactor, there is only one actuator available: the base flow rate which is used for $\mathrm{pH}$ control. Hence control degrees of freedom 
become zero, which requires the design of cascade controllers as further explored in the step 6 of this analysis (supervisory control layer design). The identified CVs, MVs and disturbances are summarized in Fig. 3.

\section{$<$ Figure 3>}

\subsection{Step 3: Ranking of controlled variables based on controllability criteria using $\mathrm{H}_{\infty}$ analysis}

Previous to this analysis, the transfer functions of the plant have been estimated (Table 2). Transfer functions are obtained by introducing a step change on each MV and recording the model output. The model output is then fitted to a first or second order model.

Once $G$ is obtained, weights for mixed sensitivity functions are defined. For definition of the weights, desired control performance properties are taken into account as follows [28]:

- Load disturbances are typically low to medium frequency signals. Good disturbance rejection requires large control action at low frequencies and, as a consequence, small $S$. $W_{P i}$ was selected as a low-pass filter:

$$
W_{P i}=\frac{0.5 s+\omega_{B i}}{s+0.01 \omega_{B i}}
$$

where $\omega_{B i}$ is the desired bandwidth for each loop. In this case, $\omega_{B i}$ was chosen as 400 day $^{-1}$ $\left(0.27 \mathrm{~min}^{-1}\right)$ and as the same for every output, considering a sampling interval of $20 \mathrm{~s}$ for each probe.

- Tight control at low frequency while keeping a limited input action is achieved with the following weight where the adjustable frequency is the previously defined bandwidth:

$$
W_{U i}=\frac{s}{s+\omega_{B i}}
$$

- Finally, the weight $W_{T}$ was defined to ensure that $\mathrm{T}$ is small at high frequencies and decrease the sensitivity to instrumental noise. Hence, the elements $W_{T i}$ are small at low frequencies but grow at high frequencies:

$$
W_{T i}=\frac{100 * s+\omega_{B i}}{s+100 \omega_{B i}}
$$

$<$ Table 2>

The solution of the mixed sensitivity stacked problem is characterized by the parameter $\gamma$ which, as mentioned, can be used as a controllability criterion. The candidates to CVs are ranked according to $\gamma$ (Table 3).

$<$ Table 3>

4.4 Step 4. Pairing of the controlled variables with the manipulated variables using relative gain array

The RGA for the best pair of CVs is presented in Table 4: 
The RGA suggests pairing the $\mathrm{pH}$ with the acid/base flow rate and the DO with the $\mathrm{k}_{\mathrm{L}}$ a as the RGA elements are closest to 1 for this pairing. Therefore, this pairing is considered suitable and will be further analyzed by the CLDG plots in the next step for disturbance rejection.

4.5 Step 5. Evaluation of the control structure based on disturbance rejection using closed-loop disturbance gain plots

The MVs were scaled around their nominal values and the disturbances $\pm 5 \%$ (ammonium load, inorganic carbon load), $\pm 20 \%$ (biodegradable COD) or $\pm 30 \%$ (flow) of their nominal values. The CVs were scaled in the following way: the maximum offset considered for the ratio TNN/TAN was \pm 0.3 . Then, the equivalent deviation in $\mathrm{DO}$ and $\mathrm{pH}$ was determined with the data from Fig. 2 , resulting in $0.01 \mathrm{~g} \mathrm{~m}^{-3}$ for DO and 0.2 units for $\mathrm{pH}$. For TAN and TNN the maximum offset was considered as $40 \mathrm{mg} / \mathrm{L}$. Details of the transfer functions for the disturbances $\left(\mathrm{G}_{\mathrm{d}}\right)$ can be found in the supplementary information (SI-3).

The CLDG plots show the gain response for different frequencies. Fig. 4 shows that, within the variation considered, the change of inorganic carbon input has the most severe effect of all the disturbances and control action would be required in every case, quite likely due to the effect that it has on $\mathrm{pH}$, and as consequence on substrate concentrations, and to the stoichiometric imbalance between TAN and TIC. On the other hand, changes in the biodegradable COD have a limited effect over the screened CVs.

The DO-pH alternative is relatively unaffected by the disturbances, with exception of the TIC input variations. This is an intuitive alternative for regulation, since they are affected mainly by one of the actuators but, as a drawback, it is difficult to link with optimization objectives.

$<$ Figure 4 $>$

According to the CLDG plots the control structure outcome of the RGA performs best in terms of disturbance rejection. Therefore, the design of a feasible regulatory control layer is suggested as shown in Fig. 5.

$<$ Figure 5 $>$

Note that steps 3, 4 and 5 have been done only for the SHARON reactor. Since the Anammox reactor is run at anoxic conditions, only one actuator can be used upon it: the addition of acid or base to regulate the $\mathrm{pH}$.

\subsection{Step 6. Controller tuning}

Once the pairing is done, the controllers have to be tuned. In this case, all controllers are PI controllers and were tuned using the IMC guidelines. Tuning parameters are shown in Table 5.

4.7 Step 7. Supervisory layer design 
The proposed control structure regulates the SHARON reactor, keeping a stable $\mathrm{pH}$ and oxygen level. However, if the influent quality varies, the effluent TNN/TAN ratio will vary, as DO and pH set points were found for a specific influent composition. Optimal operation conditions depend on the influent composition, specially the TAN influent load. To overcome this situation, a supervisory layer was proposed by Volcke et al. (2006) [12]. In this structure (Fig.6), the effluent TNN/TAN ratio is controlled by manipulating the DO set point. This cascade control loop can affect the microbial activity of AOB to convert more or less TAN when the effluent TNN/TAN ratio droops below or gets over 1.3, respectively. The ratio controller is tuned according to the IMC guidelines and the tuning parameters are shown in Table 5.

$<$ Figure 6>

In the Anammox reactor only $\mathrm{pH}$ is controlled. This strategy can effectively regulate the reactor operation but fails to address the control objective of maximizing nitrogen removal. In principle, if the TNN/TAN ratio in the feed to the Anammox reactor is kept at the optimum value, the removal of nitrogen is maximized. However, this design ratio may vary in the dynamic operation for a number of reasons: heterotrophic activity that denitrifies the influent nitrite and hence changes the relative amounts of nitrogen compounds or variation on microbial activity due to adaptation to the media or inhibition. In order to tackle those factors, a nested cascaded structure is proposed (Fig.7) where a master loop modifies the TNN/TAN ratio set point according to the concentration of nitrite and ammonia in the Anammox reactor. The objective of this control loop is to minimize the effluent nitrogen concentration. For this purpose, TAN and TNN are measured in the Anammox reactor. The controller works with the difference between TNN and TAN. The difference between TNN and TAN should be as close as possible to 0 , indicating that the influent loads of both nitrogen species are well balanced for the Anammox performance. In case there is TAN in the reactor, the controller increases the TNN/TAN ratio set point, while if TNN is present the TNN/TAN ratio is lowered. In case both TNN and TAN are high the control action will remain low, as the performance deviation is due to a limitation of the Anammox reactor, either because a process failure or to high incoming loads, and any change on the operability of the SHARON reactor will give a benefit. This new controller is also tuned using the IMC rules (Table 5). It must be borne in mind that the AnAOB bacteria, present in the second reactor, have a considerably slow growth rate. Hence, it is more convenient to reduce the disturbances upstream, before they upset the operation of the Anammox reactor. The nested cascade structure is indeed more complex than the others but the loops work at a very different frequency range, giving place to the needed time-scale separation for a suitable operation.

$<$ Figure $7>$

$<$ Table 5>

\subsection{Step 8. Evaluation}

According to Fig.10A the control structures lead to a high nitrogen removal rate, as in all the 3 cases more than $85 \%$ of the influent ammonia is removed. We consider that this is an acceptable 
performance, as the main goal of this system is to reduce the nitrogen load back to the main line in the treatment plant, where the remaining nitrogen will be further removed by conventional nitrification/denitrification.

$<$ Table 6>

\section{DISCUSSION}

Since biological processes, as wastewater treatment, are characterized by the scarcity of MVs it is important to make the right pairing between the potential CVs and the available MVs. In this study, the selection of CVs is done in two stages. First, candidates for the CVs are combined in groups of two variables (i.e. number of available actuators) and the solution to the mixed sensitivity control problem defined in equation (6) is determined for all the possible combinations of two pairs of controlled variables. This task is used as a first screening in the selection of controlled variables as it provides a criterion $(\gamma)$ that allows ordering the different alternatives in terms of controllability. Then, the best candidates are further analyzed using the RGA and in terms of disturbance rejection by CLDG plots. Following this procedure is well adapted to bioreactors because i) solving the mixed sensitivity control problem can be easily automatized (e.g. with command mixsyn from the Matlab Robust Control Toolbox); ii) automation of the CLDG plots revision is more difficult and usually requires visual inspection which requires a limited number of alternatives; and iii) even if the problem is combinatorial, the number of combinations to be tested is $\left(\begin{array}{c}n Y \\ n M V\end{array}\right)=\frac{n Y !}{n M V !(n Y-n M V) !}$ which remains numerically manageable for wastewater treatment processes. In fact, given that the number of degrees of freedom in WWTP operation is usually low, the number of combinations can be approximated as $O\left(n Y^{n M V}\right)$. Therefore, the required computational time by a typical desktop PC to carry out this method is in the order of minutes. This methodology presents some advantages with regard to others that have been already applied in this field. For instance, $H_{\infty}$ takes into account one way interactions, while the RGA fails predicting them [29]. In previous work [33] the performance RGA has been proposed as an alternative to the RGA to overcome this failure. However, we recommend the use of $H_{\infty}$, as it provides a ranking of CVs within optimal control theory framework, which facilitates the pairing of CVs and MVs when the number of candidates to CVs is large. Furthermore, the use of robust control techniques ensures the applicability of the developed control structures in real systems, despite model mismatch due to high parameter uncertainty in biological models [34, 35]. The only drawback of this methodology is that, since $\gamma$ values are dependent on the process, it is not possible to establish a threshold value to select the best pair of candidates for CVs. Therefore, it is suggested to combine this analysis together with other tools, like RGA (the discussed limitations of the RGA are overcome by it combination with $H_{\infty}$ ) or the CLDG plots. In the supporting information (SI-3 and SI-4) the RGAs and the CLDG plots for the next 3 best candidates for CVs (according to Table 3) are shown. RGAs show similar values and evident selection cannot be made based on them. This issue can be overcome by using the additional information from $H_{\infty}$, a metric which considers additionally measurement uncertainties. Hence a proper combination of $H_{\infty}$ and RGA tools support better generating promising candidates for regulatory control layer. Furthermore, the CLDG plots also confirm that the best possible 
pairing is the one proposed in Fig. 5. Therefore, we believe that the proposed protocol is systematic and also robust, as the three combined tools drive the design towards the same optimal control structure.

The results of the evaluation of the three alternative control strategies indicate that the addition of the first cascaded loop improves the regulation of the process making the production of nitrogen (and thereby the nitrogen removal) robust to the influent disturbances. The addition of the second cascade does not have a major impact on the regulation of the process but it leads to a maximization of the nitrogen removal from the system improving the percentage of nitrogen removed in $3 \%$ of the total influent nitrogen (Table 6). Besides, the addition of the cascaded structures did not increase the regulation effort in the other loops as the TV of the $\mathrm{pH}$ loop actuator in the SHARON reactor has comparable values in the 3 cases. The chosen scenario, a CANR system fed with the effluent anaerobic digester, does not offer room for significant improvement by adding the second cascade. This is simply due to low organic carbon content in the effluent of the anaerobic digester at the treatment plant. In wastewaters where the organic load is higher, as landfill leachate or wastewaters from digested animal waste, the heterotrophic denitrification plays a more important role affecting the optimal balance between nitrite and ammonia to be fed to the Anammox reactor [1, 36]. Dynamic simulations with higher influent COD were performed to test this hypothesis (Fig. 8B). As expected, the improvement on nitrogen removal by the nested cascade compared with the single cascade loop is more significant in the new scenario (nested cascade leads to $91 \%$ of nitrogen removal, while the cascade control leads to 84\%). Surprisingly, the regulatory control layer outperforms the first cascade control loop (the regulatory control layer leads to a removal of $89 \%$ of the influent). Since the ratio controller is forcing to the SHARON reactor to provide a TNN/TAN ratio of 1.3, without considering the operation of the Anammox reactor, the overall system performance may be worse than when this ratio is uncontrolled. In the chosen scenario, TNN/TAN ratio is oscillating close to the actual demand by the Anammox reactor, thereby leading to a high nitrogen removal. Both the nested cascade and the cascade control strategies reduce by $40 \%$ the aeration costs in comparison to the regulatory control layer. The chemical dosing demanded by the cascade control structure is about $40 \%$ lower than the demanded by the regulatory control layer, while the nested cascade requires $4 \%$ more. Overall, for those scenarios where high influent COD load is expected, we consider that a feedback from the Anammox reactor to the upstream SHARON reactor would lead to a high benefit in comparison with the two simpler control structures.

$<$ Figure 8 $>$

The two cascade control structures using the optimal regulatory layer design based on $H_{\infty}$ are promising and can be transferred to industrial applications successfully as the required online sensors are commonly available, which includes DO, pH, TAN and TNN [17, 37]. Moreover, while process control in wastewater treatment plants is mainly relying on process engineering insights [38], the developed control design methodology makes this work systematic and effective. In particular, the methodology incorporates modern control theory that is expected to give valuable scientific assurance and support to process engineers to develop optimal process control and operation for existing and new applications of this technology. 


\section{CONCLUSIONS}

In this study, we use a stepwise assessment and design procedure to design the control system for the SHARON-Anammox process in two reactor configuration. Based on the results obtained, we conclude that

- A novel methodology incorporating $H_{\infty}$ method combined with the RGA and CLDG plots is successfully adapted and used to design the control structure for two stage CANR process.

- The design methodology is particularly suited to address an important challenge of multivariate control structure design in WWTPs, namely optimal pairing of a small number of MVs available with CVs that are typically too many to choose from.

- $H_{\infty}$ analysis is applied as a screening tool to rank and select the best candidates for CVs. The best CVs are further analyzed using the RGA to obtain proper paring of CVs with MVs which are then verified using the CLDG plots. As a result, we design a regulatory layer composed by five feedback control loops used to keep a stable DO, pH and HRT in both reactors. The regulatory control layer leads to a nitrogen removal of $89 \%$ of the influent ammonia.

- A first supervisory control structure is designed introducing a cascade control loop. Controlling the TNN/TAN fed to the Anammox reactor by manipulating the DO controller set point yields to a nitrogen removal of $92 \%$.

- A second supervisory control structure is proposed, including a new cascade loop nested to the TNN/TAN ratio controller. By measuring the TAN and TNN in the Anammox reactor, the operation in the upstream SHARON reactor is optimized, thereby removing $95 \%$ of the influent ammonia. This last control structure enhances the nitrogen removal in the system, while keeps a comparable TV in the $\mathrm{pH}$ control loop.

- When the system is operated under high influent COD loading conditions, the nested cascade performs best, leading to a nitrogen removal of $91 \%$, while the single cascade perform worst, leading to a nitrogen removal of $84 \%$.

It should be noted that the model-based optimization may induce changes on the reactors microbial community to an extent that the process dynamic model used for control evaluation may not be applicable [39]. Therefore, future research should address the implementation of the proposed control structures in lab scale reactors (see e.g. [6]) before it is implemented in full scale systems.

\section{ACKNOLEWGEMENTS}

This research is funded, in part, by the Danish Agency for Science, Technology and Innovation through the Research Centre for Design of Microbial Communities in Membrane Bioreactors (09067230). Miguel Mauricio-Iglesias gratefully acknowledges the financial support provided by the People Program (Marie Curie Actions) of the European Union's Seventh Framework Program FP7/2007-2013 under REA agreement 627475 (GREENCOST).

\section{REFERENCES}


[1] S.W.H. Van Hulle, H.J.P. Vandeweyer, B.D. Meesschaert, P.A. Vanrolleghem, P. Dejans, A. Dumoulin, Engineering aspects and practical application of autotrophic nitrogen removal from nitrogen rich streams. Chemical Engineering Journal, 162 (2010) 1-20.

[2] A.A. Van de Graaf, A. Mulder, P. Debruijn, M.S.M. Jetten, L.A. Robertson, J.G. Kuenen, Anaerobic oxidation of ammonium is abiologically mediated process. Applied Environmental Microbiology, 61(4) (1995) 1246-1251.

[3] E.I.P. Volcke, M.C.M. van Loosdrecht, P.A. Vanrolleghem, Interaction between control and design of a SHARON reactor: economic considerations in a plant-wide (BSM2) context. Water Science and Technology, 56(9) (2007) 117-125.

[4] A. Mulder, A.A. Van De Graaf, L.A. Robertson, J.G. Kuenen, Anaerobic ammonium oxidation discovered in a denitrifying fluidized bed reactor. FEMS microbiology ecology, 16(3) (1995) 177-184.

[5] A.K. Vangsgaard, M. Mauricio-Iglesias, K.V. Gernaey, G. Sin, Development of novel control strategies for single-stage autotrophic nitrogen removal: A process oriented approach. Computers and Chemical Engineering, 66 (2014) 71-81.

[6] M. Mauricio-Iglesias, A.K. Vangsgaard, K.V. Gernaey, B.F. Smets, G. Sin, A novel control strategy for single-stage autotrophic nitrogen removal in SBR. Chemical Engineering Journal, 260 (2015) 64-73.

[7] C. Hellinga, A.A.J.C. Schellen, J.W. Mulder, M.C.M. van Loosdrecht, J.J. Heijnen, The SHARON process: An innovative method for nitrogen removal from ammonium-rich waste water. Water Science and Technology, 37(9) (1998) 135-142.

[8] J.M. Garrido, W.A.J. van Benthum, M.C.M. van Loosdrecht, J.J. Heijnen, Influence of dissolved oxygen concentration on nitrite accumulation in a biofilm airlift suspension reactor. Biotechnology and Bioengineering, 53 (1996) 168-178.

[9] A.C. Anthonisen, R.C. Loerh, T.B.S. Prakasam, E.G. Srinath, Inhibition of nitrification by ammonia and nitrous acid. Water Environment Federation, 48(5), (1976) 835-852.

[10] S. Lackner, A. Terada, B.F. Smets, Heterotrophic activity compromises autotrophic nitrogen removal in membrane-aerated biofilms: results of a modeling study. Water Research, 42(4-5) (2008) 1102-1112.

[11] S.E. Vlaeminck, A. Terada, B.F. Smets, D.V.D. Linden, N. Boon, W. Verstraete, M. Carballa, Nitrogen removal from digested black water by one-stage partial nitritation and anammox. Environmental Science and Technology, 43 (2009) 5035-5041.

[12] E.I.P. Volcke, M.C.M. van Loosdrecht, P.A. Vanrolleghem, Controlling the nitrite:ammonium ratio in a SHARON reactor in view of its coupling with an Anammox process. Water Science and Technology, 53(4-5) (2006) 45-54.

[13] A. Miot, K.R. Pagilla, Control of partial nitritation of centrate in a sequencing batch reactor. Water Environment Research, 82(9) (2010) 819-829.

[14] Z. Jemaat, A. Bartolí, E. Isanta, J. Carrera, M.E. Suárez-Ojeda, J. Pérez, Closed-loop control of ammonium concentration in nitritation: convenient for reactor operation but also for modeling. Bioresource Technology, 128 (2013) 655-663.

[15] J. A. Torà, J. Lafuente, C. García-Belinchón, L. Bouchy, J. Carrera, J. A. Baeza, Highthroughput nitritation of reject water with a novel ammonium control loop: stable effluent generation for Anammox or heterotrophic denitritation. Chemical Engineering Journal, 243 (2014) 265-271.

[16] L.W. Jaroszynski, N. Cicek, R. Sparling, J.A. Oleszkiewicz, Importance of the operating pH in maintaining the stability of anoxic ammonium oxidation (Anammox) activity in moving bed biofilm reactors. Bioresource Technology, 102 (2011) 7051-7056. 
[17] S. Lackner, W.M. Gilbert, S.E. Vlaemink, A. Joss, H. Horn, M.C.M. van Loosdrecht, Fullscale partial nitritation/Anammox experiences - An application survey. Water Research, 55 (2014) 292-303.

[18] T. Larsson, S. Skogestad, Plantwide control- A review and a new design procedure. Modeling, identification and control, 21(4) (2000) 209-240.

[19] A.C.B. Araújo, S. Gallani, M. Mulas, G. Olsson, Systematic approach to the design of operation and control policies in activated sludge systems. Industrial and Engineering Chemistry Research, 50 (2011) 8542-8557.

[20] V.C. Machado, D. Gabriel, J. Lafuente, J.A. Baeza, Cost and effluent quality controllers design based on the relative gain array for a nutrient removal WWTP. Water Research, 43 (2009) 5129-5141.

[21] C. Cadet, J.F. Béteau, S.C. Hernandez, Multicriteria control strategy for cost/quality compromise in wastewater treatment plants. Control Engineering Practice 12 (2003) 335-347.

[22] A. Galí, J. Dosta, M.C.M. van Loosdrecht, J. Mata-Alvarez, Two ways to achieve an Anammox influent from real reject water treatment at lab-scale: Partial SBR nitrification and SHARON process. Process Biochemistry, 42(4) (2007) 715-720.

[23] A.K. Vangsgaard, M. Mauricio-Iglesias, K.V. Gernaey, B.F. Smets, G. Sin, Sensitivity analysis of autotrophic $\mathrm{N}$ removal by a granule based bioreactor: Influence of mass transfer versus microbial kinetics. Bioresource Technology, 123 (2012) 230-241.

[24] G. Sin, D. Kaelin, M.J. Kampschreur, I. Takás, B. Wett, K.V. Gernaey, L. Rieger, H. Siegrist, M.C.M. van Loosdrecht, Modeling nitrite in wastewater treatment systems: a discussion of different modeling concepts. Water Science and Technology, 58(6) (2008) 1155-1171.

[25] S. Van Hulle, E.I.P. Volcke, J. López Teruel, B. Donckels, M.C.M. Van Loosdrecht, P.A. Vanrolleghem, Influence of temperature and $\mathrm{pH}$ on the process kinetics of the SHARON nitritation process. Journal of Chemical Technology and Biotechnology, 82 (2007) 471-480.

[26] A.K.Vangsgaard, M. Mauricio-Iglesias, B. Valverde-Pérez, K.V. Gernaey, G. Sin, pH variation and influence in an autotrophic nitrogen removing biofilm system using an efficient numerical solution strategy. Water Science and Technology, 67(11) (2013) 2605-2615.

[27] E. Jahanshahi, S. Skogestad, H. Hansen, Control structure design for stabilizing unstable gaslift oil wells. Proceedings of the 8th IFAC Symposium on Advanced Control of Chemical Processes, 2012.

[28] S. Skogestad, I. Postlethwaite, Multivariable Feedback Control: Analysis and Design. Wiley \& Sons, Chichester, West Sussex, UK, 2005.

[29] D.E. Seborg, T.F. Edgar, D.A. Mellichamp, Process Dynamics and Control. second ed, John Wiley and Sons Inc., 2004.

[30] M. Hovd, S. Skogestad, Simple frequency dependent tools for control system analysis, structure selection and design. Automatica, 28(5) (1992) 989-996.

[31] I. Nopens, L. Benedetti, U. Jeppsson, M.N. Pons, J. Alex, J.B. Copp, K.V. Gernaey, C. Rosen, J.-P. Steyer, P.A. Vanrolleghem, Benchmark Simulation Model No 2: Finalisation of plant layout and default control strategy. Water Science and Technology, 62(9) (2010) 1967-1974.

[32] K.V.,Gernaey, U. Jeppsson, P.A. Vanrolleghem, J.B. Copp. Benchmarking of Control Strategies for Wastewater Treatment Plants. IWA Scientific and Technical Report No. 23. London, UK: IWA Publishing, 2014.

[33] M. Mauricio-Iglesias, S.B. Jørgensen, G. Sin, A systematic methodology for controller tuning in wastewater treatment plants, Proceedings of the 8th IFAC Symposium on Advanced Control of Chemical Processes, 2012. 
[34] G. Sin, K.V. Gernaey, M.B. Neumann, M.C.M. van Losdrecht, W. Gujer., Uncertainty analysis in WWTP model applications: a critical discussion using an example for design. Water Research, 43 (2009) 2894-2906.

[35] L. R. Formenti, A. Nørregaard, A. Bolic, D. Quintanilla-Hernández, T. Hagemann, A.L. Heins, H. Larsson, L. Mears, M. Mauricio-Iglesias, U. Krühne, K.V. Gernaey, Challenges in industrial fermentation technology research. Biotechnology Journal, 9 (2014) 727-738.

[36] Y. Li, Z. Huang, W. Ruan, H. Ren, M. Zhao, ANAMMOX performance, granulation and microbial response under COD disturbance. Journal of Chemical Technology and Biotechnology, 90 (2015), 139-148.

[37] A. Mašić, A.T.L. Santos, B. Etter, K.M. Udert, K. Villez. Estimation of nitrite in sourceseparated nitrified urine with UV spectrophotometry. Water Research, 85 (2015), 244-254.

[38] P.A. Vanrolleghem, S. Guillot, Robustness and economic measures as control benchmark criteria. Water Science and Technology, 45(4-5) (2002) 117-126.

[39] G. Sin, K. Villez, P.A. Vanrolleghem, Application of a model-based optimisation methodology for nutrient removing SBRs leads to falsification of the model. Water Science and Technology, 53(4-5) (2006), 95-103. 


\section{Table and Figure captions:}

Table 1. Summary of the proposed control structure design methodology.

Table 2. Pant transfer functions (G).

Table 3. Value of $\gamma$ in the solution of the mixed sensitivity stacked problem for different combinations of controlled variables.

Table 4. Relative gain array for dissolved oxygen (DO) and $\mathrm{pH}$.

Table 5. Tuning parameters for the regulatory control layer. $K_{c}$ : controller gain; I: integral action $\left(\mathrm{K}_{\mathrm{c}} / \tau_{\mathrm{I}}\right)$

Table 6. Key performance indicators for the control structures proposed for 15 days of evaluation with the BSM2 anaerobic digester effluent. Note that the IAE of DO is comparably higher in the cascaded controllers as the set point becomes a time-varying trajectory.

Figure 1. Effluent of the anaerobic digester in the BSM2 corresponding to the summer period. a) Total nitrogen from ammonia (TAN); b) readily biodegradable COD (Ss); c) total inorganic carbon (TIC); and d) flow rate.

Figure 2. Contour plot of the molar ratio TNN/TAN in function of $\mathrm{pH}$ and DO levels at steady state.

Figure 3. Open loop block diagrams: A) SHARON reactor: GSHARON: SHARON process; GU: actuators available for control design (acid/base flow rate into the reactor and $\mathrm{k}_{\mathrm{L}} \mathrm{a}$ ); $\mathrm{D}_{1}$ : disturbances in the influent (ammonia nitrogen load, total inorganic carbon load, readily biodegradable COD, inflow rate); Y SHARON: potential controlled variables (dissolved oxygen, $\mathrm{pH}, \mathrm{TAN}, \mathrm{TNN}$, TNN/TAN); and B) Anammox reactor: GANAmmox: Anammox process; Gu: actuators available for control design (acid/base flow rate into the reactor); $\mathrm{D}_{2}$ : disturbances (effluent of the SHARON reactor); Y ANAmmox: potential controlled variables ( $\mathrm{pH}, \mathrm{TAN}, \mathrm{TNN})$. Equivalent process flow diagram is shown in SI-4.

Figure 4. Closed-loop disturbance plots for selected controlled variables DO and pH. Green: variable controlled by $k_{\mathrm{L}}$; black: variable controlled by acid/base flow rate.

Figure 5. Regulatory control layer for the SHARON-Anammox reactor sequence. Abbreviations: $\mathrm{G}_{\mathrm{C}, \mathrm{pH}}$ : $\mathrm{pH}$ controller; $\mathrm{G}_{\mathrm{C}, \mathrm{DO}}$ : dissolved oxygen controller; $\mathrm{G}_{\mathrm{SHARON}}$ : SHARON process; $\mathrm{G}_{\mathrm{d} 1}$ : process

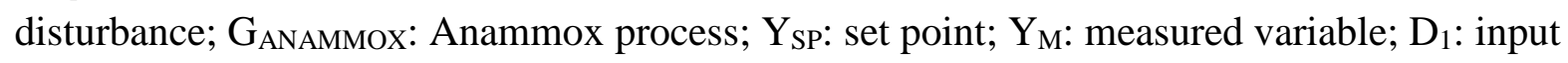
disturbance; $\mathrm{Y}_{1}$ : process output. Equivalent process flow diagram is shown in SI-4.

Figure 6. Cascade control structure for the SHARON-Anammox reactor sequence. The dissolved oxygen set point is manipulated to control the effluent TNN/TAN ratio from the SHARON reactor. Abbreviations: $\mathrm{G}_{\mathrm{C}, \mathrm{TNN} / \mathrm{TAN}}$ : TNN/TAN ratio controller (master controller); $\mathrm{G}_{\mathrm{C}, \mathrm{pH}}$ : $\mathrm{pH}$ controller;

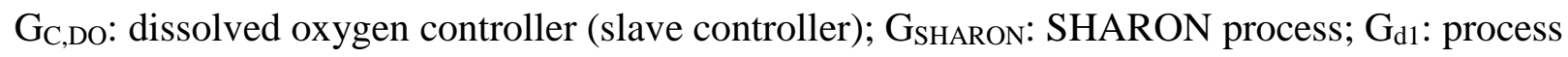




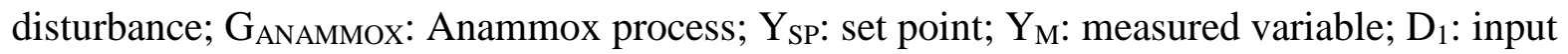
disturbance; $\mathrm{Y}_{1}$ : process output. Equivalent process flow diagram is shown in SI-4.

Figure 7. Nested cascade control structure for the SHARON-Anammox reactor sequence. The TNN/TAN set point is manipulated to control the nitrogen removal efficiency of the SHARONAnammox reactor sequence. Abbreviations: $\mathrm{G}_{\mathrm{C}, \mathrm{Neff}}$ effluent nitrogen controller (master controller of $G_{C, T N N / T A N}$ ); $G_{C, T N N / T A N}$ TNN/TAN ratio controller (slave controller of $G_{C, N e f f}$ and master controller of $\mathrm{G}_{\mathrm{C}, \mathrm{DO}}$ ); $\mathrm{G}_{\mathrm{C}, \mathrm{pH}}$ : $\mathrm{pH}$ controller; $\mathrm{G}_{\mathrm{C}, \mathrm{DO}}$ : dissolved oxygen controller (slave controller of

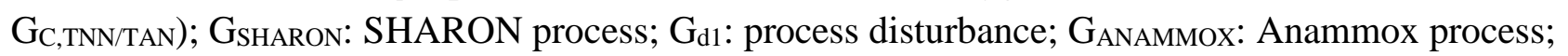
$\mathrm{Y}_{\mathrm{SP}}$ : set point; $\mathrm{Y}_{\mathrm{M}}$ : measured variable; $\mathrm{D}_{1}$ : input disturbance; $\mathrm{Y}_{1}$ : process output. Equivalent process flow diagram is shown in SI-4.

Figure 8. Production of nitrogen gas in the Anammox reactor for 30 days of evaluation with: A) the BSM2 anaerobic digester effluent (Fig.1); and B) the BSM2 anaerobic digester effluent with an average COD concentration of $300 \mathrm{~g}-\mathrm{N} \mathrm{m}^{-3}$. The results from the regulatory structure are shown as a continuous line, the results from the cascade as a dashed line and the results from the nested cascade as a dotted line. 
Table 1:

\begin{tabular}{|c|c|}
\hline Step & Output \\
\hline $\begin{array}{l}\text { 1. Goal definition and process } \\
\text { optimization }\end{array}$ & $\begin{array}{l}\text { Optimal operation conditions and set points of } \\
\text { the controllers }\end{array}$ \\
\hline 2. Degrees of freedom analysis & Identification of MVs and candidates to CVs \\
\hline 3. $\mathrm{H}_{\infty}$ analysis & Ranking of best candidates to CVs \\
\hline 4. Relative gain array (RGA) & Pairing of CVs with MVs \\
\hline 5. CLDG plots & Confirmation of the pairing given by RGA \\
\hline 6. Controller tuning & Tuning parameters of the controllers \\
\hline 7. Supervisory layer design & $\begin{array}{l}\text { Supervisory layer that relates the CVs with the } \\
\text { process objective }\end{array}$ \\
\hline 8. Evaluation & Validation of the control structure \\
\hline
\end{tabular}

Table 2:

\begin{tabular}{|c|c|c|}
\hline CV/MV & Fbase & kLa \\
\hline DO & $\frac{-2.13 \cdot 10^{3}}{(0.37 s+1)}$ & $\frac{1.44 \cdot 10^{-4}}{\left(4.010^{-2} s+1\right)\left(2.810^{-2} s+1\right)}$ \\
\hline pH & $\frac{-0.32}{(0.33 s+1)}$ & $\frac{8.29 \cdot 10^{-9}}{\left(4.010^{-2} s+1\right)\left(2.210^{-2} s+1\right)}$ \\
\hline TAN & $\frac{-5.30 \cdot 10^{7}}{(0.33 s+1)(1.03 s+1)}$ & $\frac{0.33(-0.41 s+1)}{(1.00 s+1)}$ \\
\hline TNN & $\frac{7.00 \cdot 10^{6}(-0.29 s+1)}{(0.98 s+1)(0.43 s+1)}$ & $\frac{0.56(0.22 s+1)}{(1.02 s+1)}$ \\
\hline TNN/TAN & $\frac{2.45 \cdot 10^{5}}{(0.52 s+1)(0.87 s+1)}$ & $\frac{5.0 \cdot 10^{-4}(1.74 s+1)}{(0.91 s+1)\left(3.610^{-2} s+1\right)}$ \\
\hline
\end{tabular}


Table 3:

\begin{tabular}{ll|r}
\hline \multicolumn{3}{l}{ CVs } \\
\hline DO & pH & 7.0 \\
DO & TAN & 13.3 \\
TAN & TNN/TAN & 19.5 \\
pH & TNN/TAN & 20.3 \\
DO & TNN/TAN & 24.7 \\
pH & TAN & 32.0 \\
TAN & TNN & 41.6 \\
pH & TNN & 48.9 \\
DO & TNN & 53.6 \\
TNN & TNN/TAN & 92.6 \\
\hline
\end{tabular}

Table 4:

\begin{tabular}{|l|l|l|l|}
\cline { 3 - 4 } \multicolumn{2}{c|}{} & Manipulated variables \\
\hline \multirow{3}{*}{ Controlled variables } & & Fbase & $\mathrm{k}$ La \\
\cline { 2 - 4 } & DO & -0.233 & 1.233 \\
\cline { 2 - 4 } & $\mathrm{pH}$ & 1.233 & -0.233 \\
\hline
\end{tabular}

Table 5:

\begin{tabular}{|c|c|c|}
\hline & Kc & I \\
\hline DO & 10 & 0.001 \\
\hline pHsHARON & -35 & -0.01 \\
\hline pHAnammox & $5 \cdot 10^{-9}$ & $1.23 \cdot 10^{-9}$ \\
\hline Cascade & 6 & 4 \\
\hline Nested cascade & 0.025 & 0.005 \\
\hline
\end{tabular}


Table 6:

\begin{tabular}{|c|c|c|c|c|}
\hline Structure & $\begin{array}{c}\text { Average Nitrogen } \\
\text { Removal }\end{array}$ & & DO loop & pH loop \\
\hline \multirow{3}{*}{ Regulatory } & & IAE & $5.97 \mathrm{~d}$ & $22.67 \mathrm{~d}$ \\
\hline & $89 \%$ & & & \\
\hline & & TV & $744.5 \mathrm{~d}^{-1}$ & $7.22 \cdot 10^{-4} \mathrm{~m}^{3} \mathrm{~d}^{-1}$ \\
\hline \multirow{3}{*}{ Cascade } & & IAE & $85.26 \mathrm{~d}$ & $52.03 \mathrm{~d}$ \\
\hline & $92 \%$ & & & \\
\hline & & TV & $1.06 \cdot 10^{4} \mathrm{~d}^{-1}$ & $5.07 \cdot 10^{-4} \mathrm{~m}^{3} \mathrm{~d}^{-1}$ \\
\hline \multirow{3}{*}{ Nested cascade } & & IAE & $87.90 \mathrm{~d}$ & $61.49 \mathrm{~d}$ \\
\hline & $95 \%$ & & & \\
\hline & & TV & $1.07 \cdot 10^{4} \mathrm{~d}^{-1}$ & $4.50 \cdot 10^{-4} \mathrm{~m}^{3} \mathrm{~d}^{-1}$ \\
\hline
\end{tabular}


Figure 1:
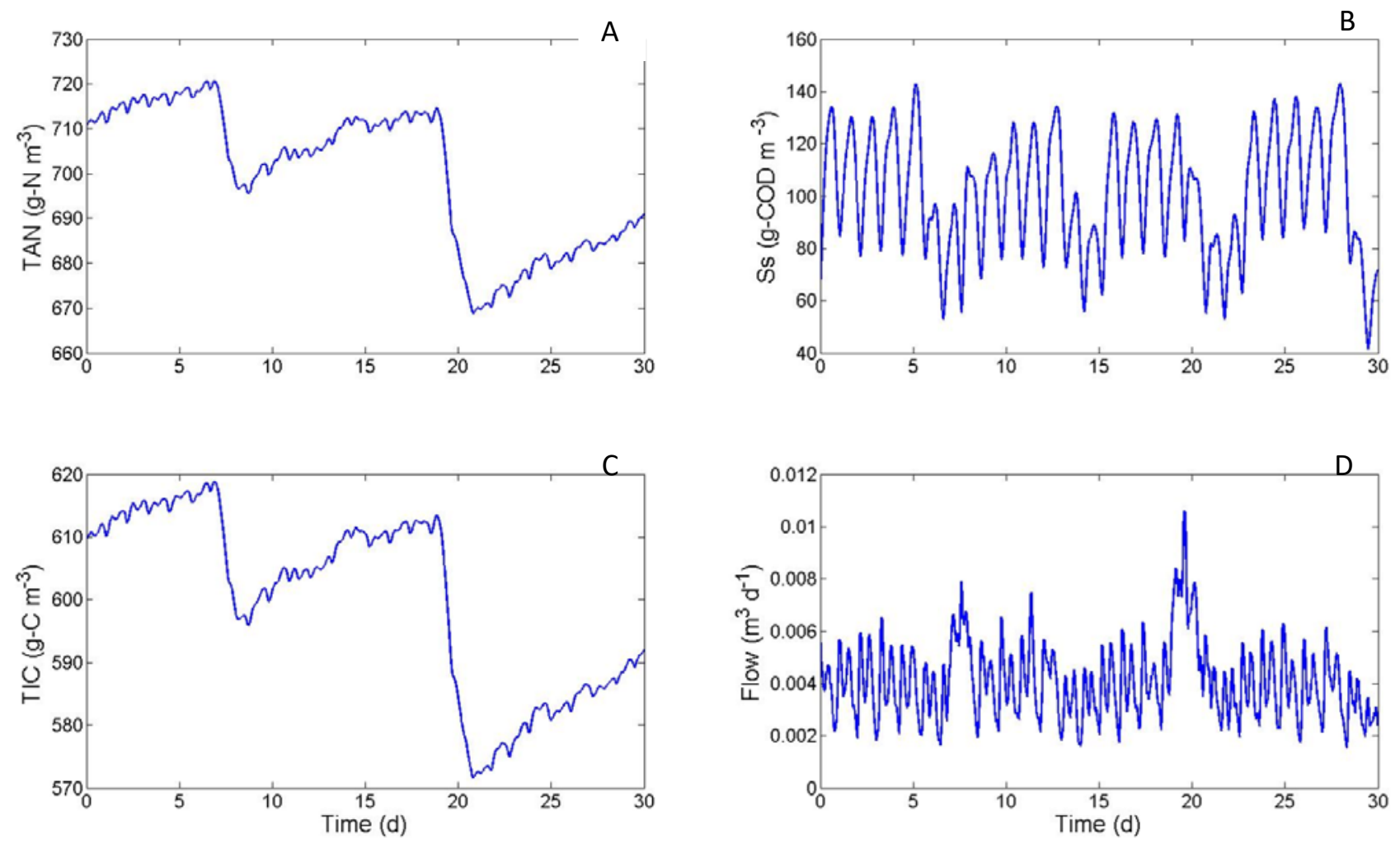

Figure 2:

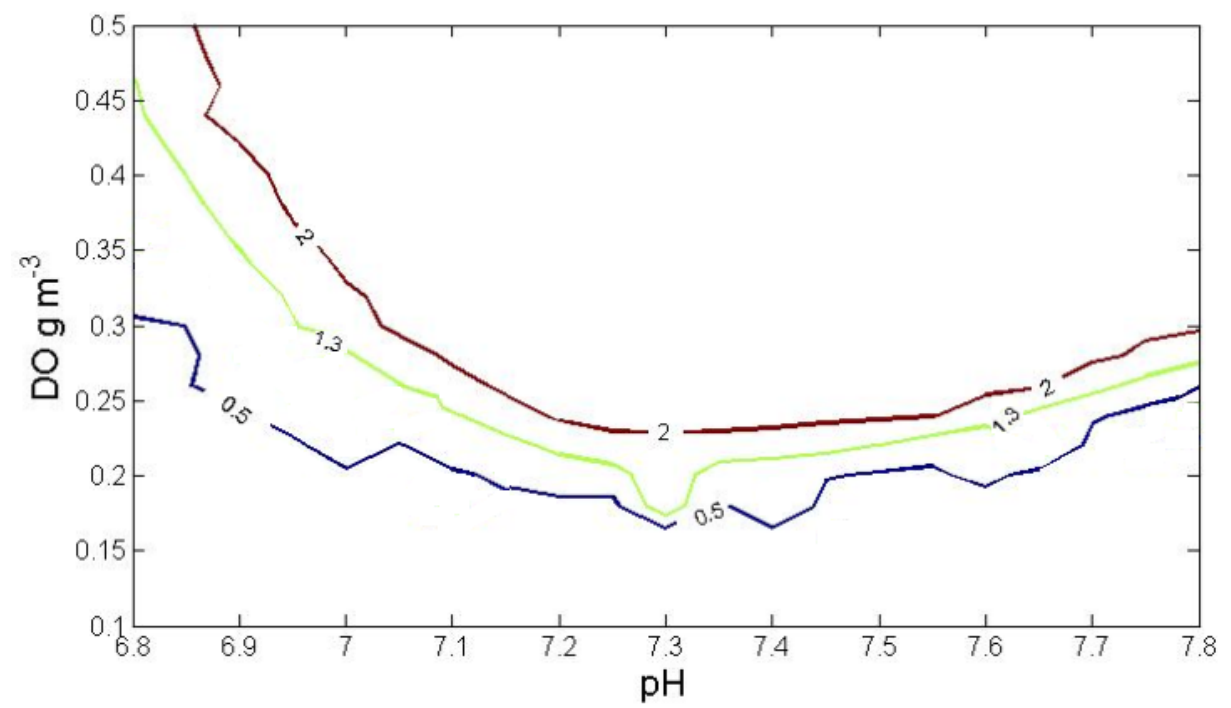


Figure 3:

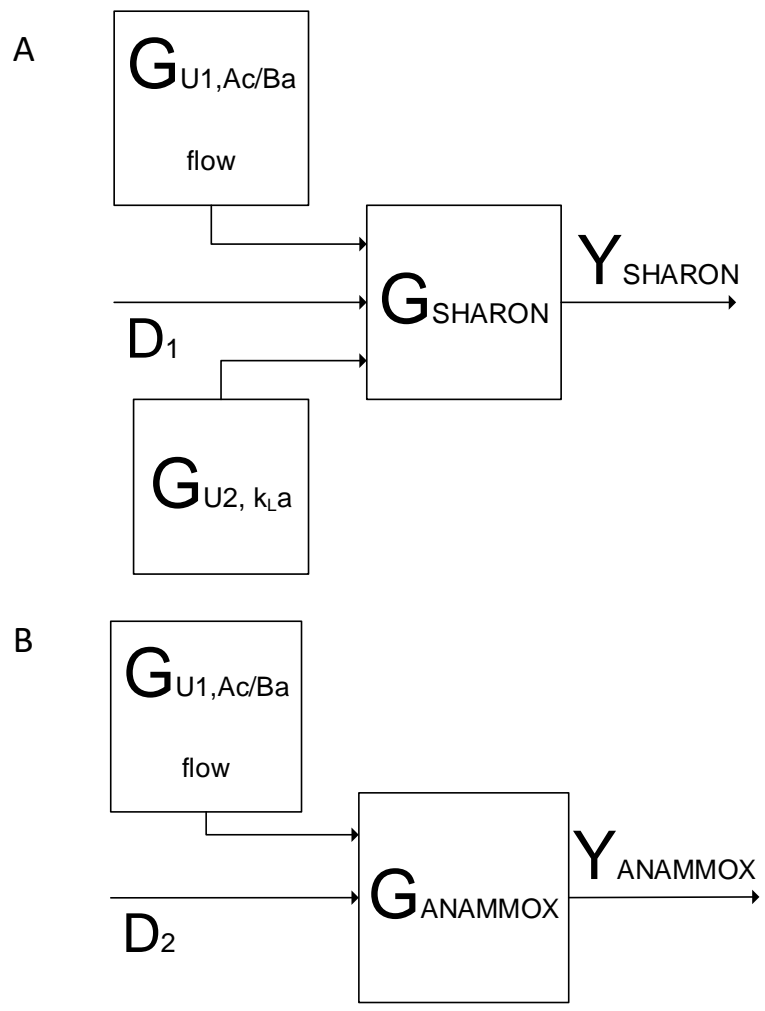


Figure 4:
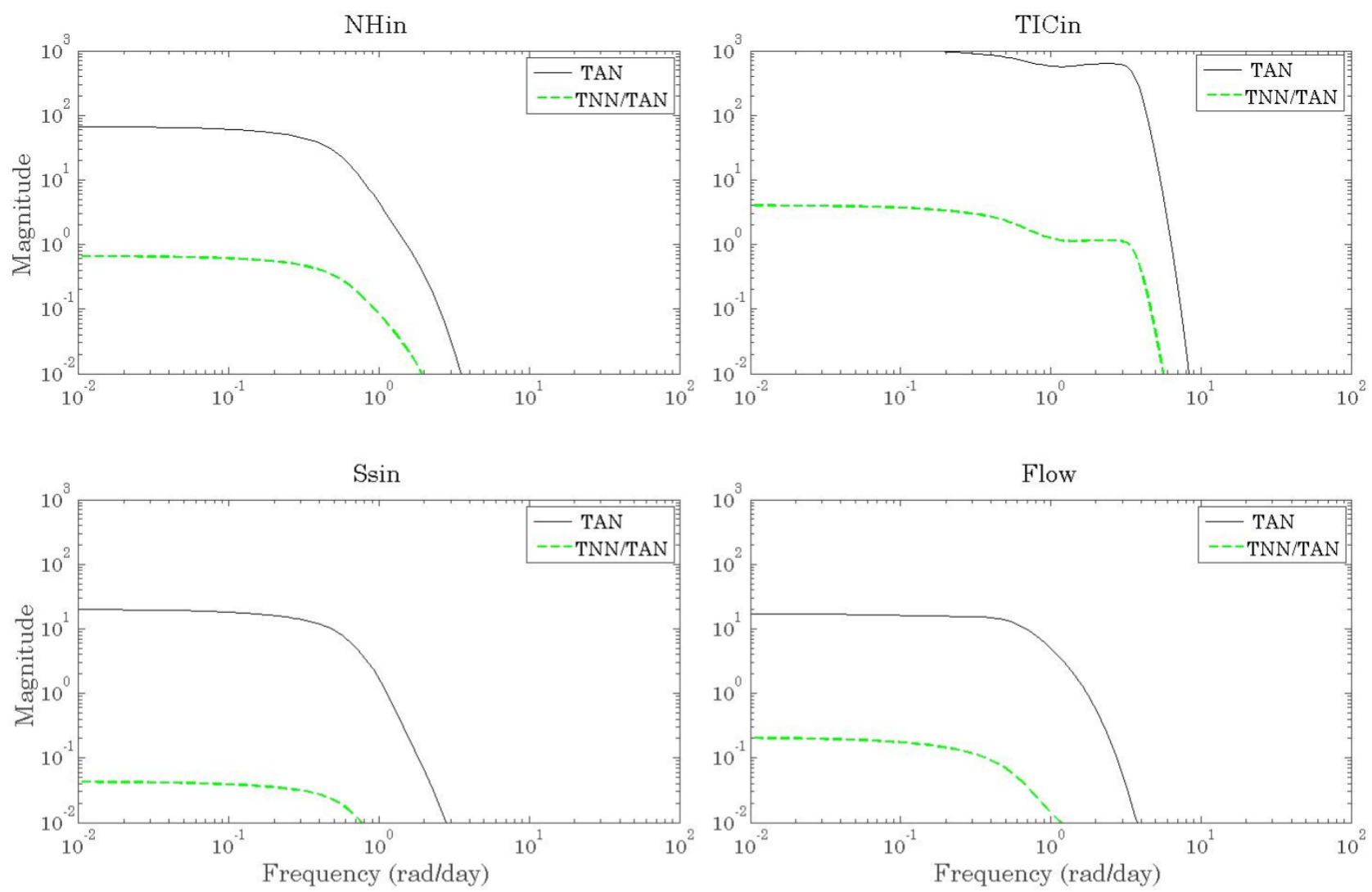

Figure 5:

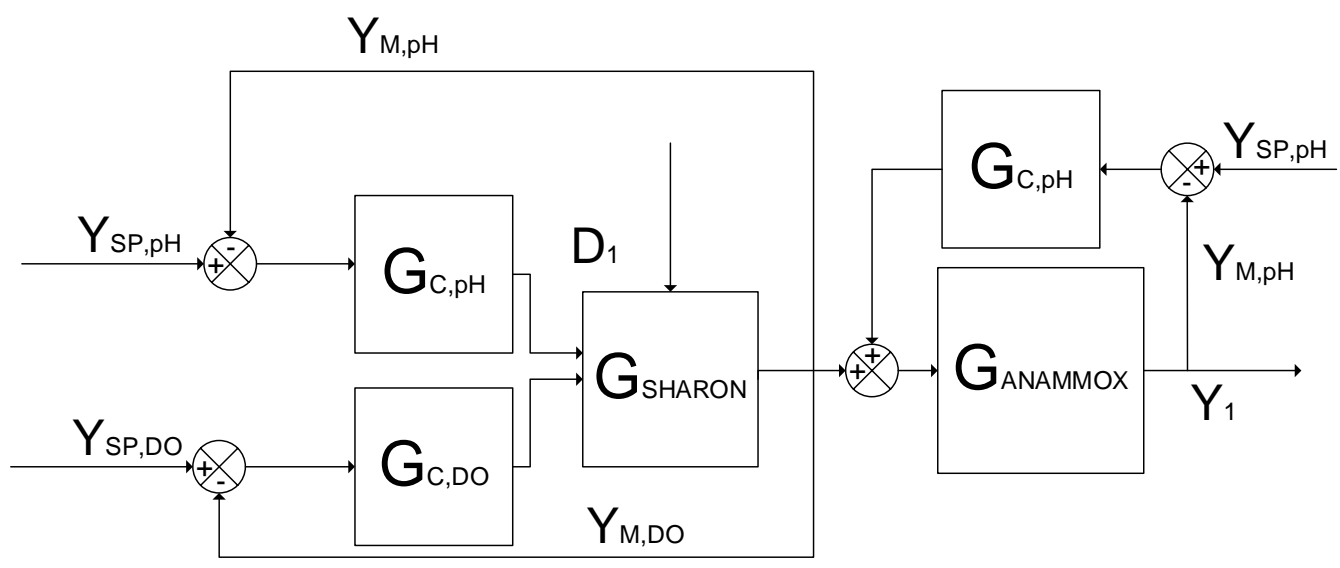


Figure 6:

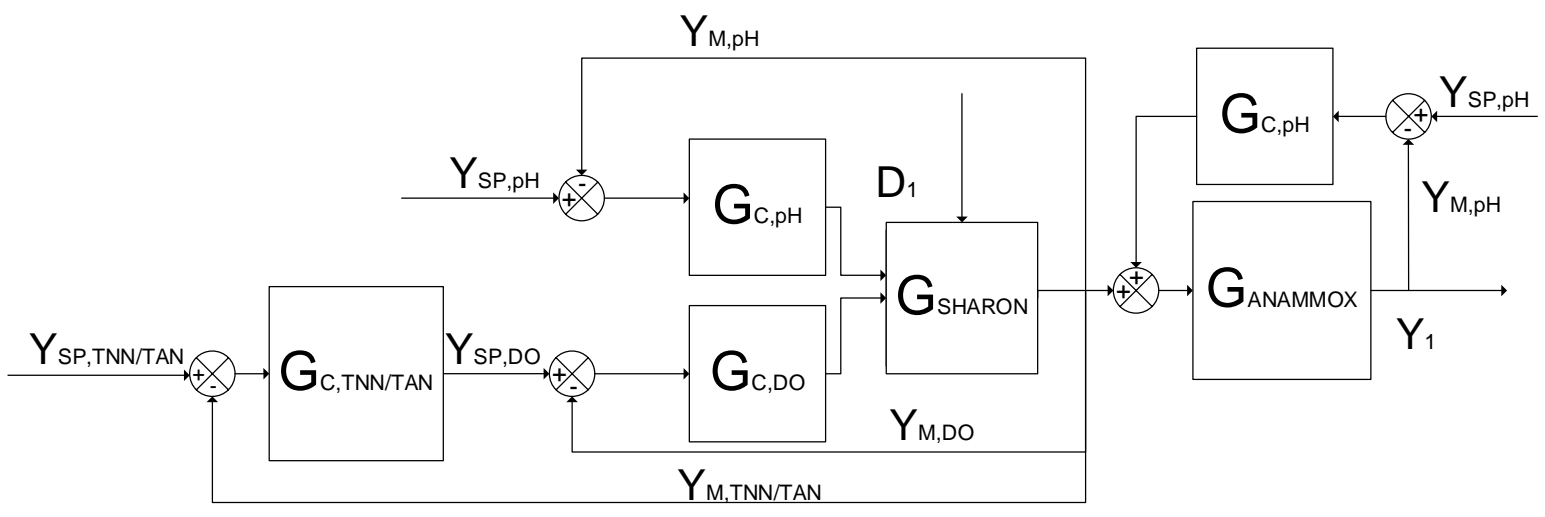

Figure 7:

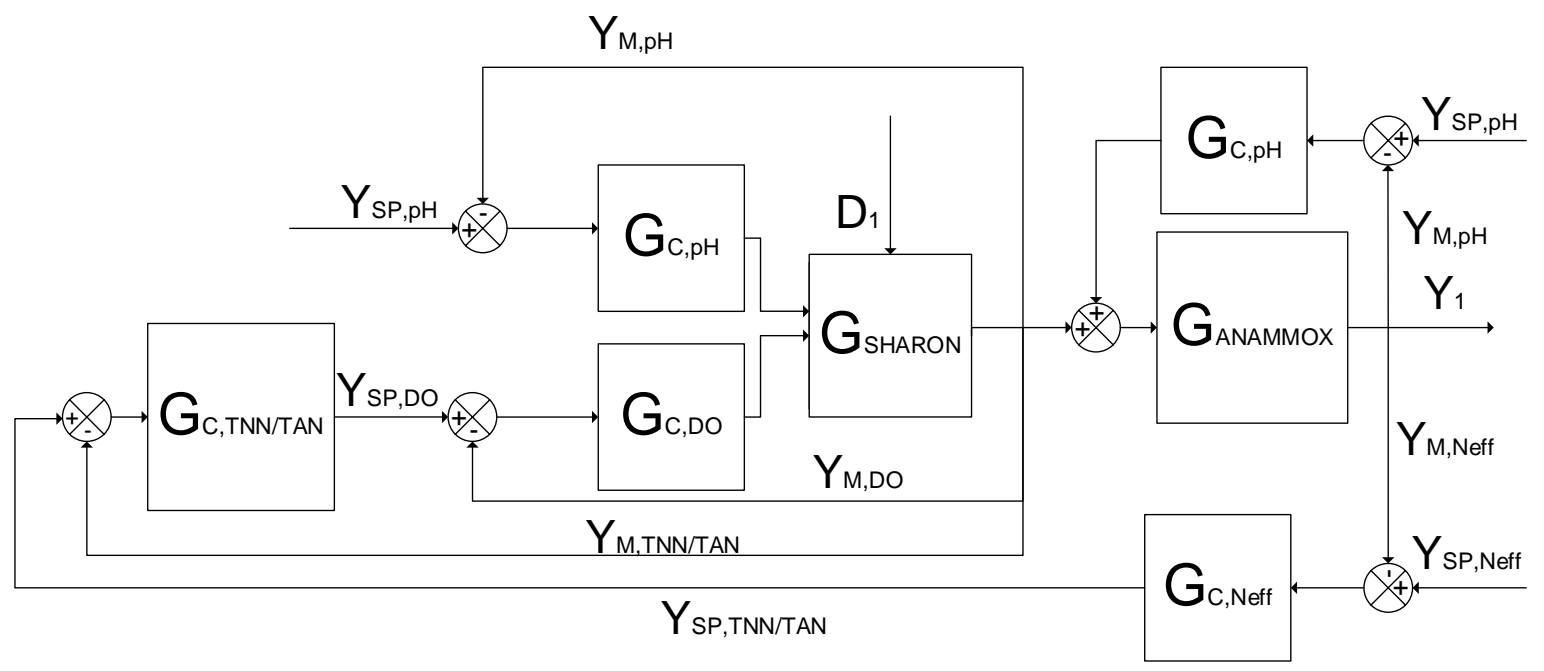


Figure 8:
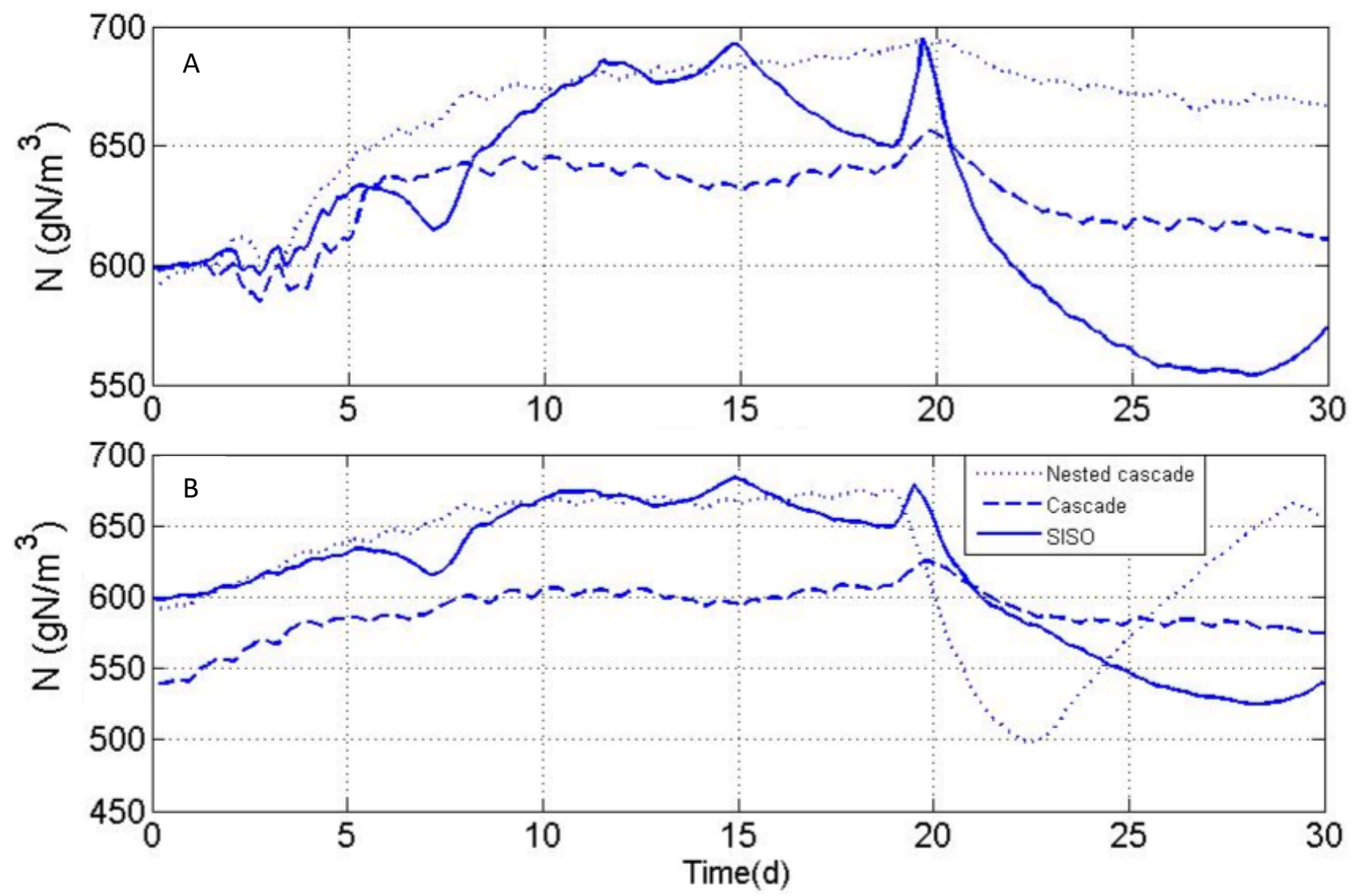
Supplementary material for:

Systematic design of an optimal control system for the SHARONAnammox process

Borja Valverde-Pérez, Miguel Mauricio-Iglesias, Gürkan Sin

SI-1 Model details

SI-2 Transfer function for the Anammox reactor

SI-3 Close loop disturbance gain plots

SI-4 Relative gain arrays

SI-5 Process flow diagrams 


\section{Supporting information:}

\section{SI-1Model details:}

Symbols and parameter values:

The biological model has been adapted from Vangsgaard et al. [1]. We use the commonly used Gujer matrix presentation of the model below. Table S1 shows the symbols and units of the different states, Table S2 shows the process rates, Table S3 shows the stoichiometry of the different processes and Table S4 and S5 show the parameter values.

Table S1: Symbols and units of the states of the model

\begin{tabular}{|l|c|c|}
\hline \multicolumn{1}{|c|}{ Compound } & Symbol & Unit \\
\hline Total ammonium nitrogen & $\mathrm{S}_{\mathrm{TAN}}$ & $\mathrm{g} \mathrm{N} \mathrm{m}^{-3}$ \\
\hline Total nitrite nitrogen & $\mathrm{S}_{\mathrm{TNN}}$ & $\mathrm{g} \mathrm{N} \mathrm{m}^{-3}$ \\
\hline Nitrate & $\mathrm{S}_{\mathrm{NO} 3}$ & $\mathrm{~g} \mathrm{~N} \mathrm{~m}^{-3}$ \\
\hline Nitrogen gas & $\mathrm{S}_{\mathrm{N} 2}$ & $\mathrm{~g} \mathrm{~N} \mathrm{~m}^{-3}$ \\
\hline Oxygen & $\mathrm{S}_{\mathrm{O} 2}$ & $\mathrm{~g} \mathrm{COD} \mathrm{m}^{-3}$ \\
\hline Readily biodegradable organic carbon & $\mathrm{S}_{\mathrm{S}}$ & $\mathrm{g} \mathrm{COD} \mathrm{m}^{-3}$ \\
\hline Aerobic ammonium oxidizing bacteria & $\mathrm{X}_{\mathrm{AOB}}$ & $\mathrm{g} \mathrm{COD} \mathrm{m}^{-3}$ \\
\hline Nitrite oxidizing bacteria & $\mathrm{X}_{\mathrm{NOB}}$ & $\mathrm{g} \mathrm{COD} \mathrm{m}^{-3}$ \\
\hline Heterotrophic bacteria & $\mathrm{X}_{\mathrm{HB}}$ & $\mathrm{g} \mathrm{COD} \mathrm{m}^{-3}$ \\
\hline Inert material & $\mathrm{X}_{\mathrm{I}}$ & $\mathrm{g} \mathrm{COD} \mathrm{m}^{-3}$ \\
\hline Particular organic material & $\mathrm{X}_{\mathrm{S}}$ & $\mathrm{g} \mathrm{COD} \mathrm{m}^{-3}$ \\
\hline
\end{tabular}

Table S2: Process rates of the biological conversion reactions considered in the CANR process

\begin{tabular}{|c|c|}
\hline Metabolic reactions: Component $i$ & Process Rate $\rho$ \\
\hline \multicolumn{2}{|l|}{ Process $k \nabla$} \\
\hline 1. AOB growth & $\mu_{\text {max,AOB }} X_{\text {AOB }} \frac{S_{\mathrm{NH} 3}}{K_{\mathrm{NH} 3, \mathrm{AOB}}+\mathrm{S}_{\mathrm{NH} 3}} \frac{\mathrm{S}_{\mathrm{O} 2}}{\mathrm{~K}_{\mathrm{O} 2, \mathrm{AOB}}+\mathrm{S}_{\mathrm{O} 2}} \frac{\mathrm{K}_{\mathrm{I}, \mathrm{HNO}, \mathrm{AOB}}}{\mathrm{K}_{\mathrm{I}, \mathrm{HNO}, \mathrm{AOB}}+\mathrm{S}_{\mathrm{HNO} 2}}$ \\
\hline 2. NOB growth & $\mu_{\mathrm{max}, \mathrm{NOB}} \mathrm{X}_{\mathrm{NOB}} \frac{\mathrm{S}_{\mathrm{HNO2}}}{\mathrm{K}_{\mathrm{HNO} 2, \mathrm{NOB}}+\mathrm{S}_{\mathrm{HNO2}}} \frac{\mathrm{S}_{\mathrm{O} 2}}{\mathrm{~K}_{\mathrm{O} 2, \mathrm{NOB}}+\mathrm{S}_{\mathrm{O} 2}}$ \\
\hline 3. AnAOB growth & $\mu_{\text {max, }, \text { AnAOB }} X_{\text {AnAOB }} \frac{\mathrm{S}_{\mathrm{NH} 3}}{\mathrm{~K}_{\mathrm{NH} 3, \mathrm{AnAOB}}+\mathrm{S}_{\mathrm{NH} 3}} \frac{\mathrm{S}_{\mathrm{HNO} 2}}{\mathrm{~K}_{\mathrm{HNO}, \text { AnAOB }}+\mathrm{S}_{\mathrm{HNO} 2}} \frac{\mathrm{K}_{1, \mathrm{O} 2, \mathrm{AnAOB}}}{\mathrm{K}_{1,02, \mathrm{AnAOB}}+\mathrm{S}_{\mathrm{O} 2}}$ \\
\hline 4. AOB decay & $\mathrm{b}_{\mathrm{AOB}} \mathrm{X}_{\mathrm{AOB}}$ \\
\hline 5. NOB decay & $\mathrm{b}_{\mathrm{NOB}} \mathrm{x}_{\mathrm{NOB}}$ \\
\hline 6. AnAOB decay & $\mathrm{b}_{\mathrm{AnAOB}} \mathrm{X}_{\mathrm{AnAOB}}$ \\
\hline 7. HB growth 1 & $\mu_{\text {max }, \mathrm{HB}} \mathrm{X}_{\mathrm{HB}} \frac{\mathrm{S}_{\mathrm{O} 2}}{\mathrm{~K}_{\mathrm{O} 2, \mathrm{HB}}+\mathrm{S}_{\mathrm{O} 2}} \frac{\mathrm{S}_{\mathrm{S}}}{\mathrm{K}_{\mathrm{S}, \mathrm{HB}}+\mathrm{S}_{\mathrm{S}}} \frac{\mathrm{S}_{\mathrm{TAN}}}{\mathrm{S}_{\mathrm{TAN}}+\mathrm{K}_{\mathrm{TAN}, \mathrm{HB}}}$ \\
\hline 8. HB growth 2 & $\mu_{\text {max }, H B} X_{H B} \eta_{H} \frac{S_{S}}{K_{S, H B}+S_{S}} \frac{S_{T N N}}{K_{T N N, H B}+S_{T N N}} \frac{K_{1,02, H B}}{K_{1,02, H B}+S_{O 2}} \frac{S_{T A N}}{S_{T A N}+K_{T A N, H B}}$ \\
\hline
\end{tabular}




\begin{tabular}{|l|l|}
\hline 9. HB growth 3 & $\mu_{\text {max, } \mathrm{HB}} \mathrm{X}_{\mathrm{HB}} \eta_{\mathrm{H}} \frac{\mathrm{S}_{\mathrm{S}}}{\mathrm{K}_{\mathrm{S}, \mathrm{HB}}+\mathrm{S}_{\mathrm{S}}} \frac{\mathrm{S}_{\mathrm{NO}}}{\mathrm{K}_{\mathrm{NO}, \mathrm{HB}}+\mathrm{S}_{\mathrm{NO}}} \frac{\mathrm{K}_{\mathrm{LO}, \mathrm{O}, \mathrm{HB}}}{\mathrm{K}_{\mathrm{L}, 02, \mathrm{HB}}+\mathrm{S}_{\mathrm{O} 2}} \frac{\mathrm{S}_{\mathrm{TAN}}}{\mathrm{S}_{\mathrm{TAN}}+\mathrm{K}_{\mathrm{TAN}, \mathrm{HB}}}$ \\
\hline 10. HB decay & $\mathrm{b}_{\mathrm{HB}} \mathrm{X}_{\mathrm{HB}}$ \\
\hline 11. Hydrolysis & $\mathrm{k}_{\mathrm{H}} \frac{\mathrm{X}_{\mathrm{S}}}{\mathrm{K}_{\mathrm{x}}}$ \\
\hline 12. Aeration & $\mathrm{k}_{\mathrm{L}} \mathrm{a}\left(\mathrm{S}_{\mathrm{O} 2, \text { Sat }}-\mathrm{S}_{\mathrm{O} 2, \mathrm{bulk}}\right)$ \\
\hline
\end{tabular}


Table S3: Stoichiometric matrix of the biological conversion reactions considered in the CANR process

\begin{tabular}{|c|c|c|c|c|c|c|c|c|c|c|c|c|}
\hline $\begin{array}{l}\text { Stoichiometric coefficients } \\
\text { Component } i\end{array}$ & $\begin{array}{l}S_{\text {TAN }} \\
1 \\
\end{array}$ & $\begin{array}{l}\mathrm{S}_{\mathrm{O} 2} \\
2\end{array}$ & $\begin{array}{l}S_{T N N} \\
3\end{array}$ & $\begin{array}{l}S_{\text {NO3 }} \\
4 \\
4\end{array}$ & $\begin{array}{l}S_{N 2} \\
5\end{array}$ & $\begin{array}{l}S_{S} \\
6\end{array}$ & $\begin{array}{l}X_{A O B} \\
7 \\
\end{array}$ & $\begin{array}{l}X_{N O B} \\
8\end{array}$ & $\begin{array}{l}X_{A n A O B} \\
9\end{array}$ & $\begin{array}{l}X_{H B} \\
10 \\
\end{array}$ & $\begin{array}{l}X_{S} \\
11 \\
\end{array}$ & $\begin{array}{l}x_{1} \\
12\end{array}$ \\
\hline Process $k \nabla$ & $\mathrm{g} \mathrm{N} \mathrm{m}^{-3}$ & $\mathrm{gCOD} \mathrm{m}^{-3}$ & $\mathrm{~g} \mathrm{~N} \mathrm{~m}^{-3}$ & $\mathrm{~g} \mathrm{~N} \mathrm{~m}^{-}$ & $\begin{array}{l}\mathrm{g} \mathrm{N} \\
\mathrm{m}^{-3}\end{array}$ & $\mathrm{gCOD} \mathrm{m}^{-}$ & $\begin{array}{l}\mathrm{gCOD} \\
\mathrm{m}^{-3}\end{array}$ & $\begin{array}{l}\mathrm{gCOD} \mathrm{m}^{-} \\
3\end{array}$ & $\mathrm{gCOD} \mathrm{m}^{-}$ & $\begin{array}{l}\mathrm{gCOD} \\
\mathrm{m}^{-3}\end{array}$ & $\begin{array}{l}11 \\
\mathrm{gCOD} \mathrm{m}^{-}\end{array}$ & $\begin{array}{l}\mathrm{gCOD} \\
\mathrm{m}^{-3}\end{array}$ \\
\hline 1. AOB growth & $-\frac{1}{Y_{A O B}}-i_{N \times B}$ & $-\frac{3.43-Y_{\triangle O B}}{Y_{A O B}}$ & $\frac{1}{\mathrm{Y}_{\mathrm{AOB}}}$ & & & & 1 & & & & & \\
\hline 2. NOB growth & $-\mathrm{i}_{\mathrm{NXB}}$ & $-\frac{1.14-Y_{\text {NOB }}}{Y_{\text {NOB }}}$ & $-\frac{1}{Y_{\mathrm{NOB}}}$ & $\frac{1}{\mathrm{Y}_{\text {NОВ }}}$ & & & & 1 & & & & \\
\hline 3. AnAOB growth & $-\frac{1}{Y_{A \cap A O B}}-i_{\text {NXB }}$ & & $-\frac{1}{Y_{\text {АПАОB }}}-\frac{1}{1.14}$ & $\frac{1}{1.14}$ & $\frac{2}{Y_{A \cap A O B}}$ & & & & 1 & & & \\
\hline 4. AOB decay & & & & & & & -1 & & & & $1-f_{i}$ & $f_{i}$ \\
\hline 5. NOB decay & & & & & & & & -1 & & & $1-f_{i}$ & $f_{i}$ \\
\hline 6. AnAOB decay & & & & & & & & & -1 & & $1-f_{i}$ & $f_{i}$ \\
\hline 7. HB growth 1 & $-\mathrm{i}_{\mathrm{NXB}}$ & $-\frac{1-Y_{\mathrm{HB}}}{\mathrm{Y}_{\mathrm{HB}}}$ & & & & $-\frac{1}{Y_{\text {нв }}}$ & & & & 1 & & \\
\hline 8. HB growth 2 & $-\mathrm{i}_{\mathrm{NXB}}$ & & $-\frac{1-Y_{\mathrm{HB}}}{1.71 Y_{\mathrm{HB}}}$ & & $\frac{1-Y_{\mathrm{HB}}}{1.71 Y_{\mathrm{HB}}}$ & $-\frac{1}{Y_{\text {НВ }}}$ & & & & 1 & & \\
\hline 9. HB growth 3 & $-\mathrm{i}_{\mathrm{NXB}}$ & & & $-\frac{1-Y_{\mathrm{HB}}}{2.86 \mathrm{Y}_{\mathrm{HB}}}$ & $\frac{1-Y_{\mathrm{HB}}}{2.86 \mathrm{Y}_{\mathrm{HB}}}$ & $-\frac{1}{Y_{\text {нв }}}$ & & & & 1 & & \\
\hline 10. HB decay & & & & & & & & & & -1 & $1-f_{i}$ & $f_{i}$ \\
\hline 11. Hydrolysis & $\frac{i_{N \times B}-f_{i} i_{N \times 1}}{1-f_{i}}$ & & & & & 1 & & & & & -1 & \\
\hline$N$ composition ( $g \mathrm{~N} / \mathrm{g}$ default unit) & 1 & 0 & 1 & 1 & 1 & 0 & $i_{N \times B}$ & $i_{N X B}$ & $i_{N X B}$ & $i_{N \times B}$ & $\frac{i_{N \times B}-f_{i} i_{N \times 1}}{1-f_{i}}$ & $i_{N X I}$ \\
\hline COD composition ( $g$ COD/g default unit) & 0 & -1 & -3.43 & -4.57 & -1.71 & 1 & 1 & 1 & 1 & 1 & 1 & 1 \\
\hline
\end{tabular}


Table S4: Kinetic parameter and their default value

\begin{tabular}{|c|c|c|c|c|}
\hline Parameter & Symbol & Value & Unit & Reference \\
\hline Max growth rate of $A O B$ & $\mu_{\max , \mathrm{AOB}}$ & $0.8 \mathrm{e}^{-0.094(293-\mathrm{T})}$ & $d^{-1}$ & Hao et al., 2002 [2] \\
\hline Oxygen half saturation constant $A O B$ & КО2,АОВ & 0.3 & $\mathrm{~g} \mathrm{COD} \mathrm{m}^{-3}$ & Wiesmann, 1994 [3] \\
\hline Ammonia half saturation constant $A O B$ & $\mathrm{~K}_{\mathrm{NH} 3, \mathrm{AOB}}$ & 0.75 & $\mathrm{~g} \mathrm{~N} \mathrm{~m}^{-3}$ & Van Hulle, 2005 [4] \\
\hline Nitrous acid inhibition constant $A O B$ & $\mathrm{~K}_{\mathrm{I}, \mathrm{HNO}, \mathrm{AOB}}$ & 2.04 & $\mathrm{~g} \mathrm{~N} \mathrm{~m}^{-3}$ & Van Hulle, 2005 [4] \\
\hline Decay rate $A O B$ & $b_{A O B}$ & $0.05 e^{-0.094(293-T)}$ & $d^{-1}$ & Hao et al., 2002 [2] \\
\hline Max growth rate NOB & $\mu_{\max , N O B}$ & $0.79 \mathrm{e}^{-0.061(293-\mathrm{T})}$ & $d^{-1}$ & Hao et al., 2002 [2] \\
\hline Oxygen half saturation constant NOB & Kо2,NOB & 1.1 & $\mathrm{~g} \mathrm{COD} \mathrm{m}^{-3}$ & Wiesmann, 1994 [3] \\
\hline Nitrous acid half saturation constant NOB & KHNO2,NOB & 0.27 & $\mathrm{~g} \mathrm{~N} \mathrm{~m}^{-3}$ & Wiesmann, 1994 [3] \\
\hline Decay rate NOB & $b_{\text {NOB }}$ & $0.033 \mathrm{e}^{-0.061(293-\mathrm{T})}$ & $d^{-1}$ & Hao et al., 2002 [2] \\
\hline Max growth rate AnAOB & $\mu_{\max , A n A O B}$ & $0.028 \mathrm{e}^{-0.096(293-\mathrm{T})}$ & $d^{-1}$ & Hao et al., 2002 [2] \\
\hline Ammonia half saturation constant AnAOB & $\mathrm{K}_{\mathrm{NH} 3, \mathrm{AnAOB}}$ & $5.33 \cdot 10^{-3}$ & $\mathrm{~g} \mathrm{~N} \mathrm{~m}^{-3}$ & Van Hulle, 2005 [4] \\
\hline $\begin{array}{l}\text { Nitrous acid half saturation constant } \\
\qquad A n A O B\end{array}$ & KHNO2,AnAOB & $1.69 \cdot 10^{-5}$ & $\mathrm{~g} \mathrm{~N} \mathrm{~m}^{-3}$ & Van Hulle, 2005 [4] \\
\hline Oxygen inhibition constant AnAOB & KO2,AпAOB & 0.01 & $\mathrm{~g} \mathrm{COD} \mathrm{m}^{-3}$ & Strous et al., 1999[5] \\
\hline Decay rate $A n A O B$ & $b_{\text {AnAOB }}$ & $0.001 \mathrm{e}^{-0.096(293-\mathrm{T})}$ & $d^{-1}$ & Hao et al., 2002 [2] \\
\hline Max growth rate HB & $\mu_{\max , \mathrm{HB}}$ & $6 \mathrm{e}^{-0.069(293-\mathrm{T})}$ & $d^{-1}$ & Henze et al., 2000[7] \\
\hline Oxygen half saturation constant $\mathrm{HB}$ & Ко2,HB & 0.2 & $\mathrm{~g} \mathrm{COD} \mathrm{m}^{-3}$ & Henze et al., 2000[7] \\
\hline $\begin{array}{l}\text { Organic substrate half saturation constant } \\
\qquad \text { HB }\end{array}$ & $\mathrm{Ks}, \mathrm{AOB}$ & 20 & $\mathrm{~g} \mathrm{COD} \mathrm{m}^{-3}$ & Henze et al., 2000[7] \\
\hline Nitrite half saturation constant HB & $\mathrm{K}_{\mathrm{NO} 2, \mathrm{HB}}$ & 0.5 & $\mathrm{~g} \mathrm{COD} \mathrm{m}^{-3}$ & Henze et al., 2000[7] \\
\hline Nitrate half saturation constant HB & $\mathrm{K}_{\mathrm{NO}, \mathrm{HB}}$ & 0.5 & $\mathrm{~g} \mathrm{COD} \mathrm{m}^{-3}$ & Henze et al., 2000[7] \\
\hline Ammonium half saturation constant HB & $\mathrm{K}_{\mathrm{TAN}, \mathrm{HB}}$ & 0.01 & $\mathrm{~g} \mathrm{~N} \mathrm{~m}^{-3}$ & Henze et al., 2000[7] \\
\hline Anoxic correction factor & $\eta$ Пн & 0.8 & - & Henze et al., 2000[7] \\
\hline Decay rate $\mathrm{HB}$ & $\mathrm{b}_{\mathrm{HB}}$ & $0.62 \mathrm{e}^{-0.113(293-\mathrm{T})}$ & $d^{-1}$ & Henze et al., 2000[7] \\
\hline
\end{tabular}




\begin{tabular}{|c|c|c|c|c|}
\hline Parameter & Symbol & Value & Unit & Reference \\
\hline AOB growth yield & $\mathrm{Y}_{\mathrm{AOB}}$ & 0.21 & $\mathrm{~g} \operatorname{COD}(\mathrm{g} \mathrm{N})^{-1}$ & Wiesmann, 1994 [3] \\
\hline NOB growth yield & $\mathrm{Y}_{\mathrm{NOB}}$ & 0.059 & g COD $\left(\mathrm{g} \mathrm{N}^{-1}\right.$ & Wiesmann, 1994 [3] \\
\hline AnAOB growth yield & $Y_{\text {AnAOB }}$ & 0.159 & $\mathrm{~g} \operatorname{COD}(\mathrm{g} \mathrm{N})^{-1}$ & Strous et al., 1998[6] \\
\hline HB growth yield & $\mathrm{Y}_{\mathrm{HB}}$ & 0.67 & g COD (g COD) $)^{-1}$ & Henze et al., 2000[7] \\
\hline Inert content in biomass & $f_{i}$ & 0.08 & 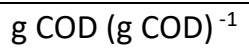 & Henze et al., 2000[7] \\
\hline Nitrogen content in inert & $\mathbf{i}_{\mathrm{NXI}}$ & 0.06 & $\mathrm{~g} \mathrm{~N}(\mathrm{~g} \mathrm{COD})^{-1}$ & Henze et al., 2000[7] \\
\hline Nitrogen content in biomass & $\mathrm{i}_{\mathrm{NXB}}$ & 0.086 & g N (g COD) $)^{-1}$ & Henze et al., 2000[7] \\
\hline
\end{tabular}

Table S5: Stoichiometric parameters and their default values

\section{Mass transfer modeling:}

Absorption or stripping only applies for $\mathrm{O}_{2}$ and $\mathrm{CO}_{2}$. The partition coefficients of both components were determined by Henry's law (Eq. (7), [8]).

$C_{i}^{*}=\frac{C_{G, i}^{\circ}}{m_{i}}$

where $\mathrm{C}_{\mathrm{G}, \mathrm{i}}{ }^{\circ}$ is the compound concentration in gas phase, and $\mathrm{m}_{\mathrm{i}}$ is the Henry coefficient. $\mathrm{CO}_{2}$ stripping is modeled as function of the $k_{\llcorner}$a for $\mathrm{O}_{2}$ (Eq. (8)), as suggested by Sin and Vanrolleghem [9].

$\mathrm{k}_{\mathrm{L}} \mathrm{a}_{\mathrm{CO}_{2}}=\mathrm{k}_{\mathrm{L}} \mathrm{a}_{\mathrm{O}_{2}} \cdot \sqrt{\frac{\mathrm{D}_{\mathrm{CO}_{2}}}{\mathrm{D}_{\mathrm{O}_{2}}}}=\mathrm{k}_{\mathrm{L}} \mathrm{a}_{\mathrm{O}_{2}} \cdot 0.91$

$\mathrm{pH}$ calculation and influence in the microbial growth rate:

The $\mathrm{pH}$ is determined solving the corresponding mass balances (Eq. (3)), equilibrium equations (Eq. (4)) and charge balance (Eq. (5)). The resulted system of 13 nonlinear equations is solved by a multidimensional Newton-Raphson method adapted from Vangsgaard et al. [10].

$$
\begin{aligned}
& 0=\mathrm{TNH}-\left(\mathrm{NH}_{4}^{+}+\mathrm{NH}_{3}\right) \\
& 0=\mathrm{TNO}-\left(\mathrm{HNO}_{2}+\mathrm{NO}_{2}^{-}\right)
\end{aligned}
$$


$0=\mathrm{TIC}-\left(\mathrm{CO}_{2}+\mathrm{HCO}_{3}^{-}+\mathrm{CO}_{3}^{-}\right)$

$0=\mathrm{K}_{\mathrm{w}}-\mathrm{OH}^{-} \cdot \mathrm{H}^{+}$

$0=\mathrm{K}_{\mathrm{e}, \mathrm{NH} 4} \cdot \mathrm{NH}_{4}^{+}-\mathrm{NH}_{3} \cdot \mathrm{H}^{+}$

$0=\mathrm{K}_{\mathrm{e}, \mathrm{HNO} 2} \cdot \mathrm{HNO}_{2}-\mathrm{NO}_{2}^{-} \cdot \mathrm{H}^{+}$

$0=\mathrm{K}_{\mathrm{e}, \mathrm{CO} 2} \cdot \mathrm{CO}_{2}-\mathrm{HCO}_{3}^{-} \cdot \mathrm{H}^{+}$

$0=\mathrm{K}_{\mathrm{e}, \mathrm{HCO} 3} \cdot \mathrm{HCO}_{3}^{-}-\mathrm{CO}_{3}^{2-} \cdot \mathrm{H}^{+}$

$0=\mathrm{Z}^{+}-\mathrm{NO}_{3}^{-}-\mathrm{HCO}_{3}^{-}-2 \cdot \mathrm{CO}_{3}^{2-}-\mathrm{NO}_{2}^{-}-\mathrm{OH}^{-}+\mathrm{NH}_{4}^{+}+\mathrm{H}^{+}$

In order to account with the impact of $\mathrm{pH}$ on bacterial activity, maximum microbial growth rate of the different bacterial groups is modeled as suggested by van Hulle et al. [11].

$\mu=\mu_{\max } \frac{\mathrm{K}_{\mathrm{pH}}}{\left.\mathrm{K}_{\mathrm{pH}^{-1+10}}\right|^{\left|\mathrm{pH}_{\mathrm{opt}}-\mathrm{pH}\right|}}$

Simulink implementation of the SHARON-Anammox process:

Fig. S1 shows the Simulink implementation of the SHARON-Anammox sequence with the regulatory control layer. Starting from the left side, the first orange block is the SHARON reactor. The influent to the SHARON reactor is loaded from the workspace. The 2 inputs shown in the diagram are the actuators. On the upper side of the SHARON reactor, it is placed the feedback control loop to control the proton concentration (instead of $\mathrm{pH}$ ). The control action calculated by the PI controlled is added to the default base influent flow rate. If after adding the control action the value becomes negative, it simulates the influent flow rate for the acid. On the lower side of the SHARON reactor, it is placed the feedback control loop for dissolved oxygen (DO). Since volume is variable (i.e. volume is a model state) the DO is estimated by dividing the total mass of oxygen in the reactor by the volume. The control action is added to the default $k \mathrm{k} a$ being the result always positive. The SHARON reactor is connected to a second orange block, which is the Anammox reactor. Below the Anammox reactor it is placed the $\mathrm{pH}$ control loop, which works as the $\mathrm{pH}$ control loop for the SHARON reactor. 


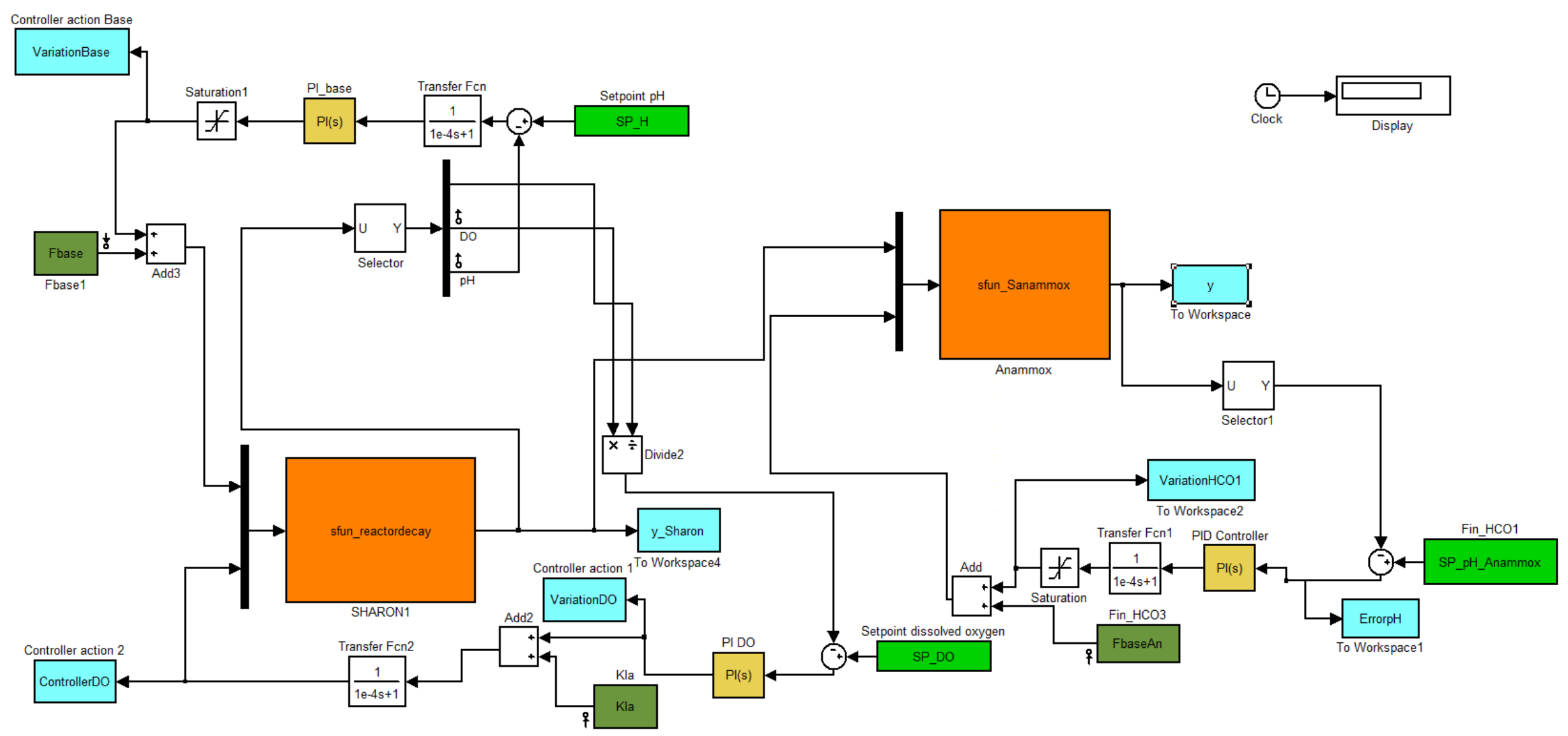

Figure S1- Simulink implementation of the SHARON-Anammox sequence with the regulatory control layer. Light green block: set points of the controllers; light blue blocks: output blocks to the workspace; orange blocks: reactor functions, including the biological model described above for continuous stirred tank reactors; yellow block: PI controller; dark green: default values for actuators. 
SI-2 Transfer function for the Anammox reactor ( $\mathrm{NaOH} 50 \%$ flow rate is the input and $\mathrm{pH}$ is the output):

$$
\frac{9.8356 \cdot 10^{6}}{(4.0514 s+1)}
$$

SI-3 Close loop disturbance gain plots:

In order to obtain the transfer functions a step disturbance is introduced in the system and the model output is fitted to first and second order models. The transfer functions are shown in table S6.

Table S6: Transfer functions for the disturbances $\left(G_{d}\right)$ :

\begin{tabular}{|l|l|l|l|l|}
\hline CV/D & TAN $_{\text {in }}$ & TIC $_{\text {in }}$ & Ss $_{\text {in }}$ & Fin $_{\text {in }}$ \\
\hline DO & $\frac{-0.37 \cdot 10^{-6}(3.1 s+1)}{(0.11 s+1)(0.37 s+1)}$ & $\frac{4.89 \cdot 10^{-4}(-0.36 s+1)}{0.44 s^{2}+0.86 s+1}$ & $\frac{3.02 \cdot 10^{-6}(1.51 s+1)}{(0.41 s+1)(1.02 s+1)}$ & $\frac{0.44(-0.65 s+1)}{(1.09 s+1)^{2}}$ \\
\hline
\end{tabular}




\begin{tabular}{|l|c|c|c|c|}
\hline $\mathbf{H}$ & $\frac{-4.010^{-10}}{0.75 s+1}$ & $\frac{-1.04 \cdot 10^{-9}(0.34 s+1)}{\left(8.010^{-2} s+1\right)(0.51 s+1)}$ & $\frac{-2.0 \cdot 10^{-9}}{1.29 s+1}$ & $\frac{-1.0 \cdot 10^{-4}}{(1.00 s+1)}$ \\
\hline TAN & $\frac{0.98}{1.02 s+1}$ & $\frac{6.49(-0.45 s+1)}{1.39 s^{2}+1.68 s+1}$ & $\frac{-7.60 \cdot 10^{-3}(4.60 s+1)}{1.39 s^{2}+1.35 s+1}$ & $\frac{1.77 \cdot 10^{4}}{(1.74 s+1)}$ \\
\hline TNN & $\frac{2.80 \cdot 10^{3}(0.57 s+1)}{0.69 s^{2}+1.10 s+1}$ & $\frac{-5.89(-0.49 s+1)}{1.44 s^{2}+1.66 s+1}$ & $\frac{-0.20}{(0.11 s+1)(1.18 s+1)}$ & $\frac{-1.17 \cdot 10^{4}}{1.47 s+1}$ \\
\hline TNN/TAN & $\frac{-3.30 \cdot 10^{-3}}{0.918 s+1}$ & $\frac{-2.0 \cdot 10^{-2}(-0.40 s+1)}{0.85 s^{2}+1.40 s+1}$ & $\frac{-6.0 \cdot 10^{-4}}{(0.19 s+1)(1.37 s+1)}$ & $\frac{-110}{1.78 s+1}$ \\
\hline
\end{tabular}



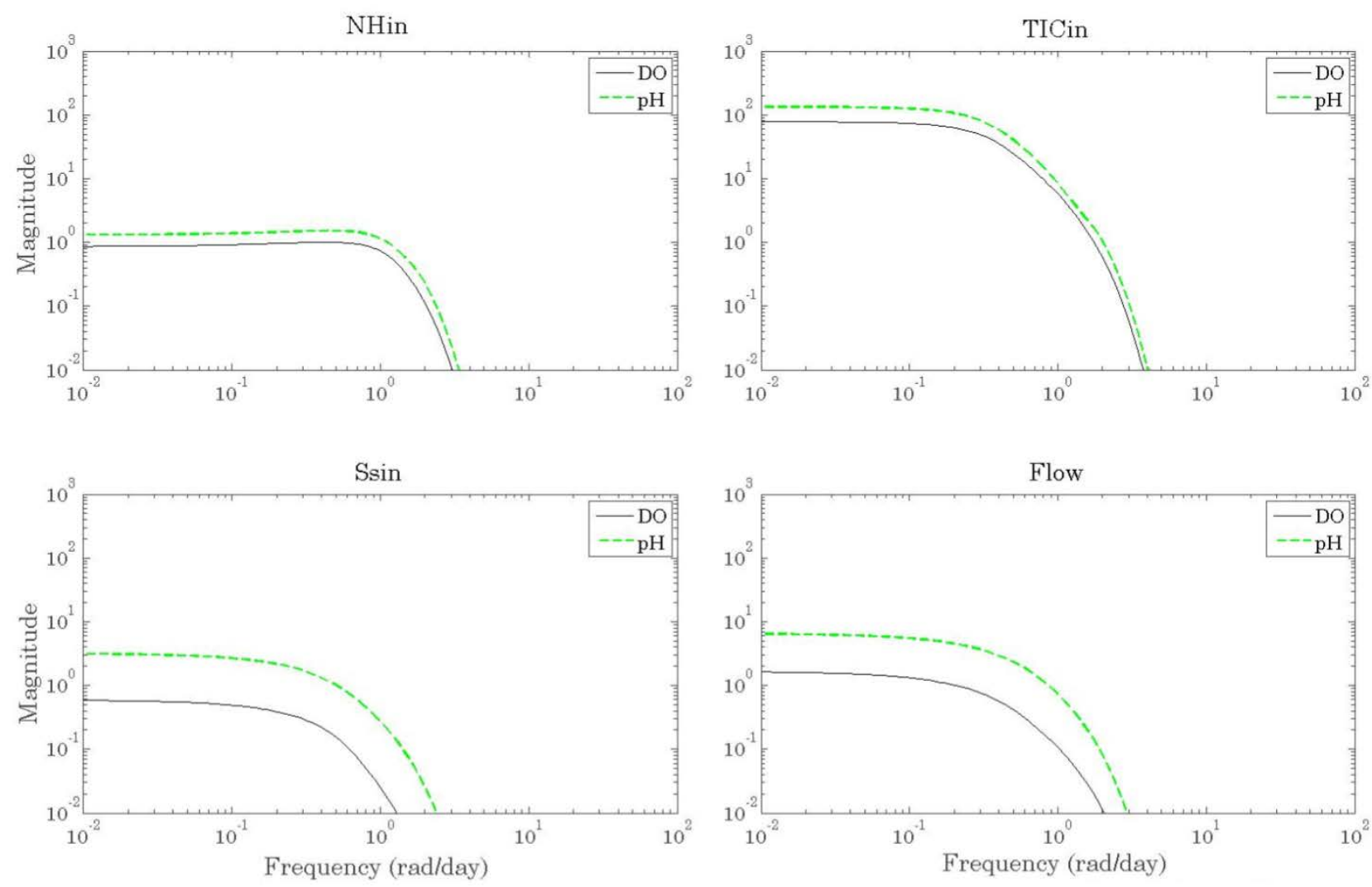

Figure S2- Closed-loop disturbance plots for selected controlled variables DO and pH. Green: variable 3 controlled by $k_{\llcorner} a$; black: variable controlled by acid/base flow rate.
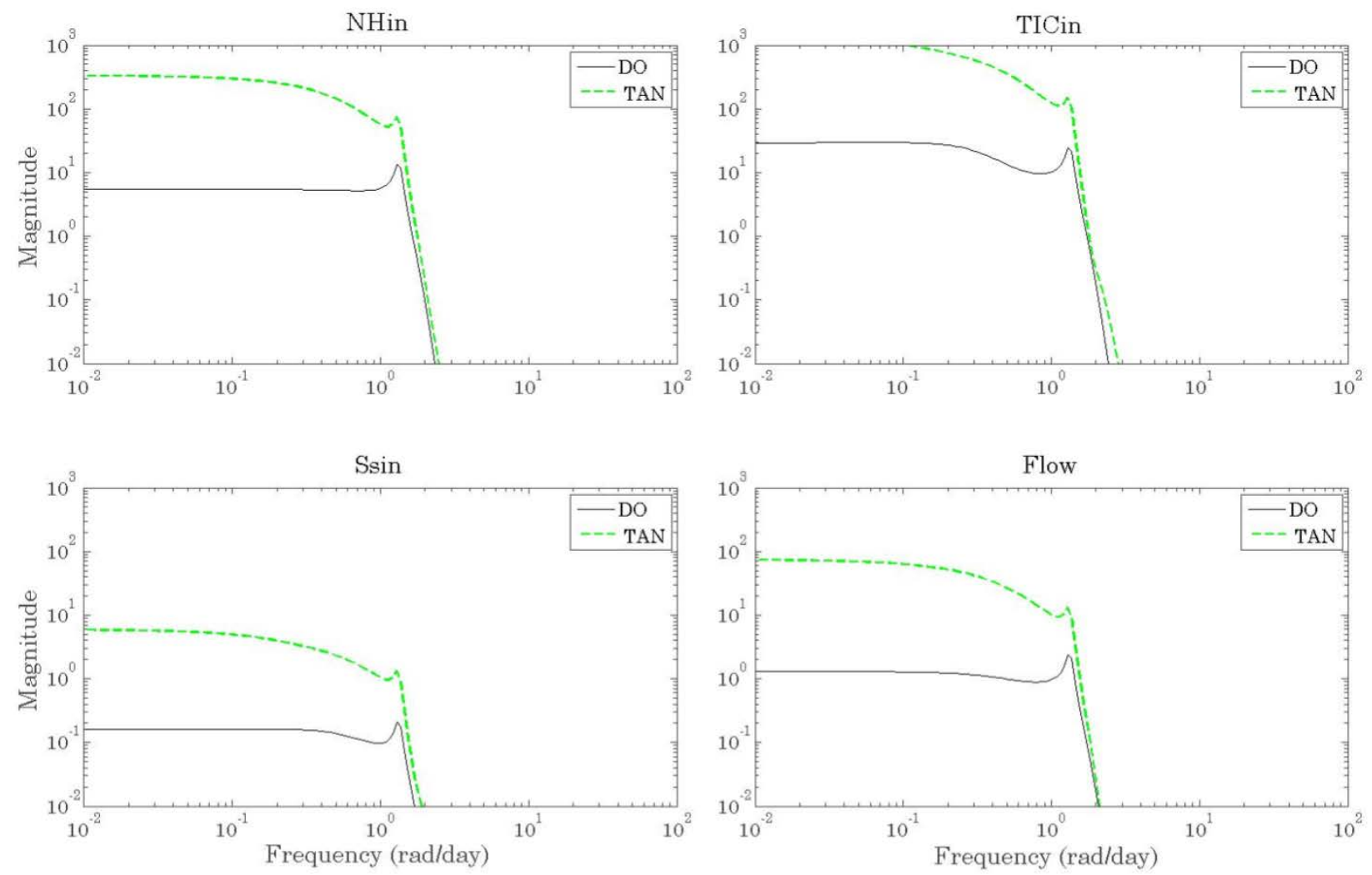
5 Figure S3-Closed-loop disturbance plots for selected controlled variables DO and TAN. Green: variable 6 controlled by $k_{\llcorner} a$; black: variable controlled by acid/base flow rate.
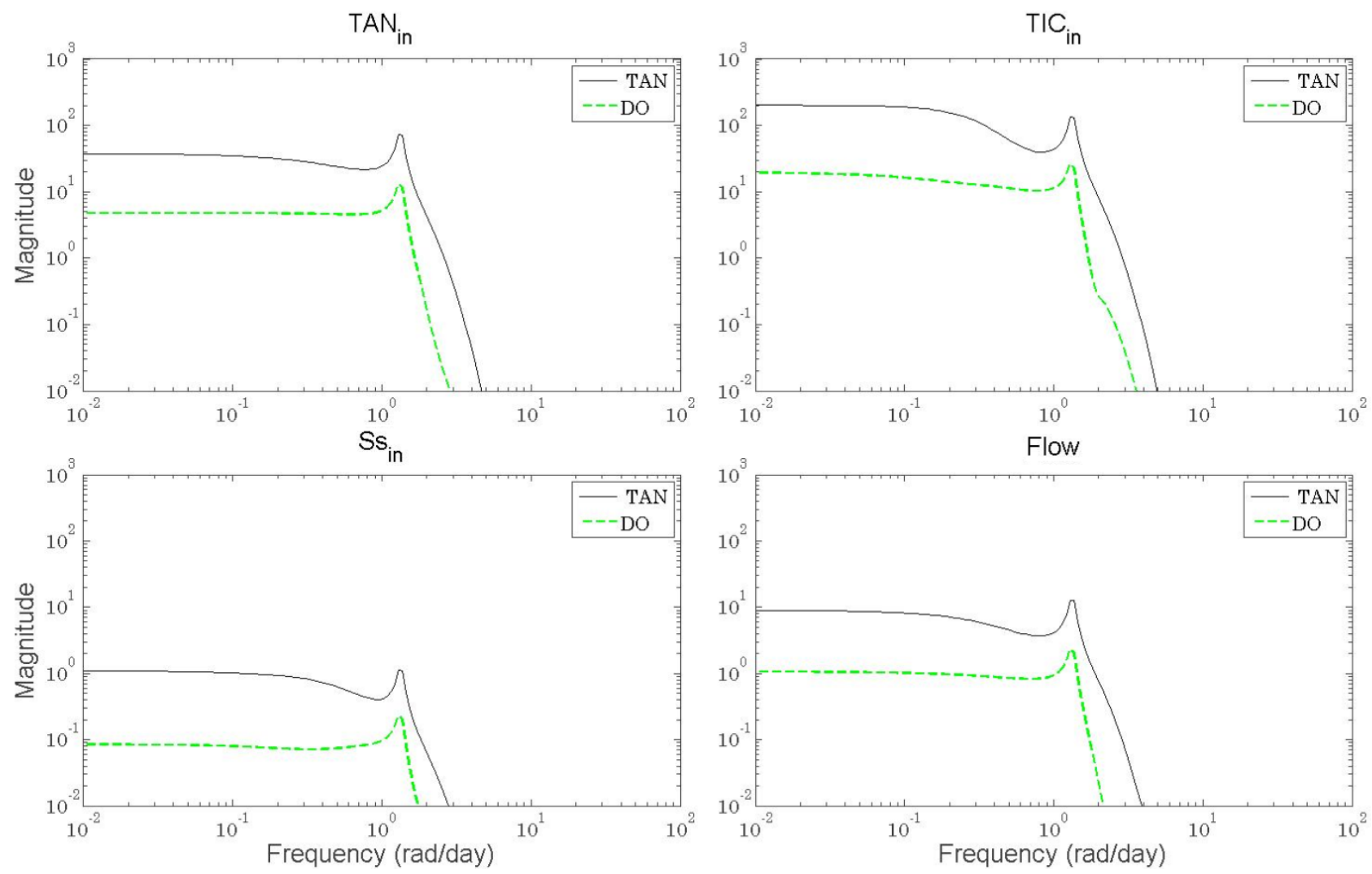

8 Figure S-4. Closed-loop disturbance plots for selected controlled variables DO and TAN. Green: variable 9 controlled by kıa; black: variable controlled by acid/base flow rate. 

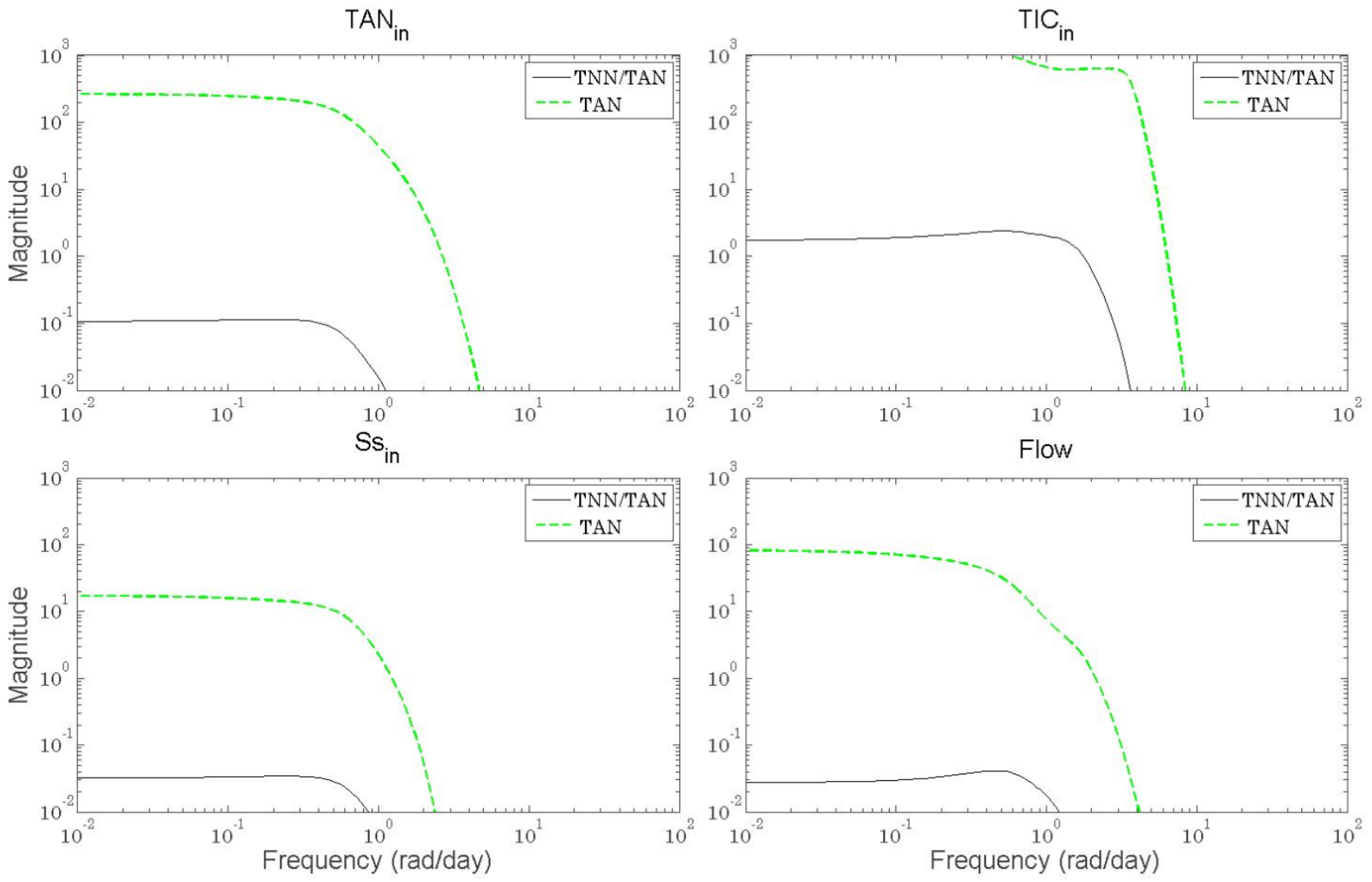

Figure S-5. Closed-loop disturbance plots for selected controlled variables TAN and TNN/TAN. Green: variable controlled by $\mathrm{k}_{\mathrm{L} a}$; black: variable controlled by acid/base flow rate. 

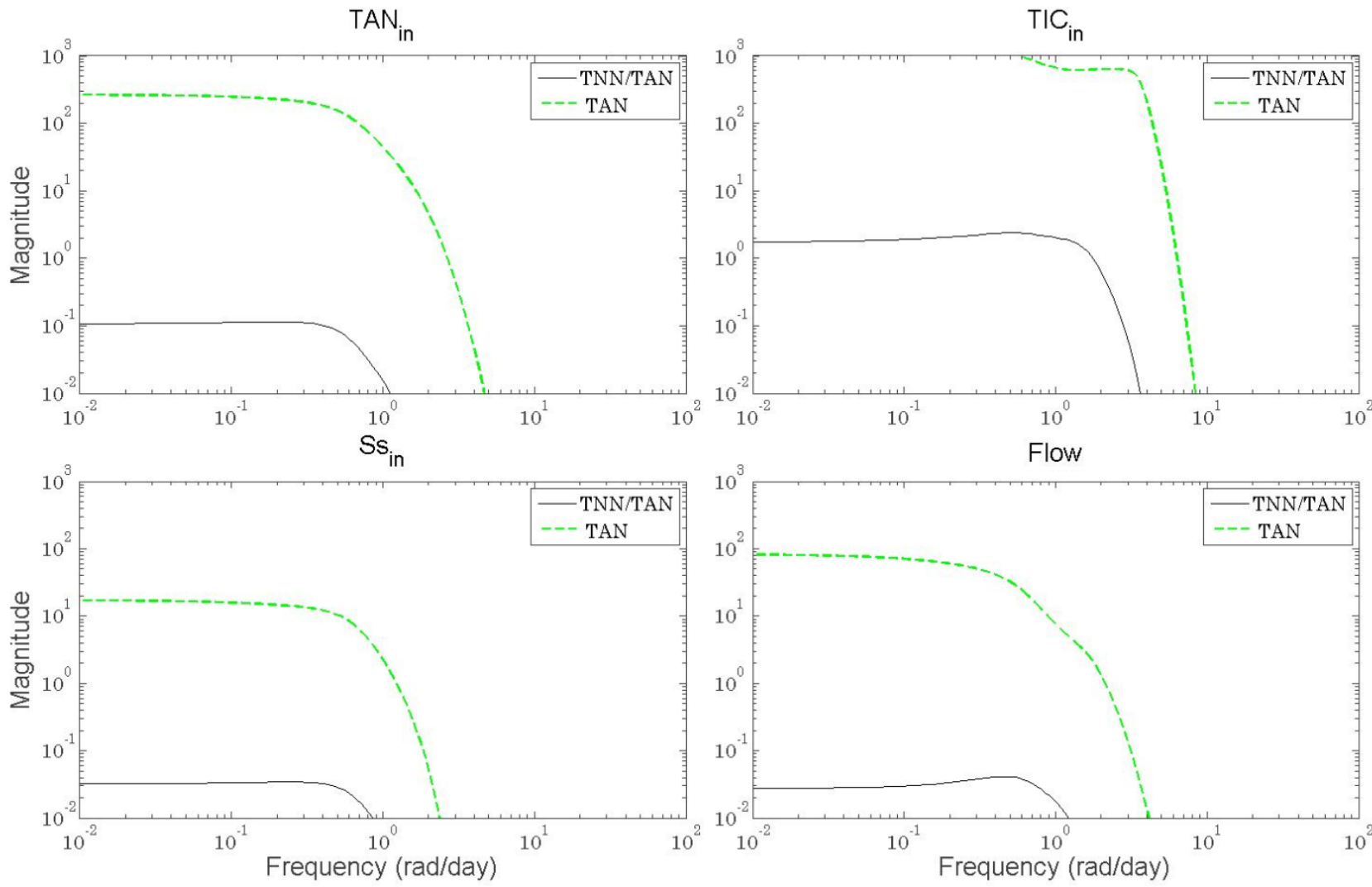

Figure S-6 Closed-loop disturbance plots for selected controlled variables TNN/TAN and TAN. Green: variable controlled by $k_{\llcorner} a$; black: variable controlled by acid/base flow rate.
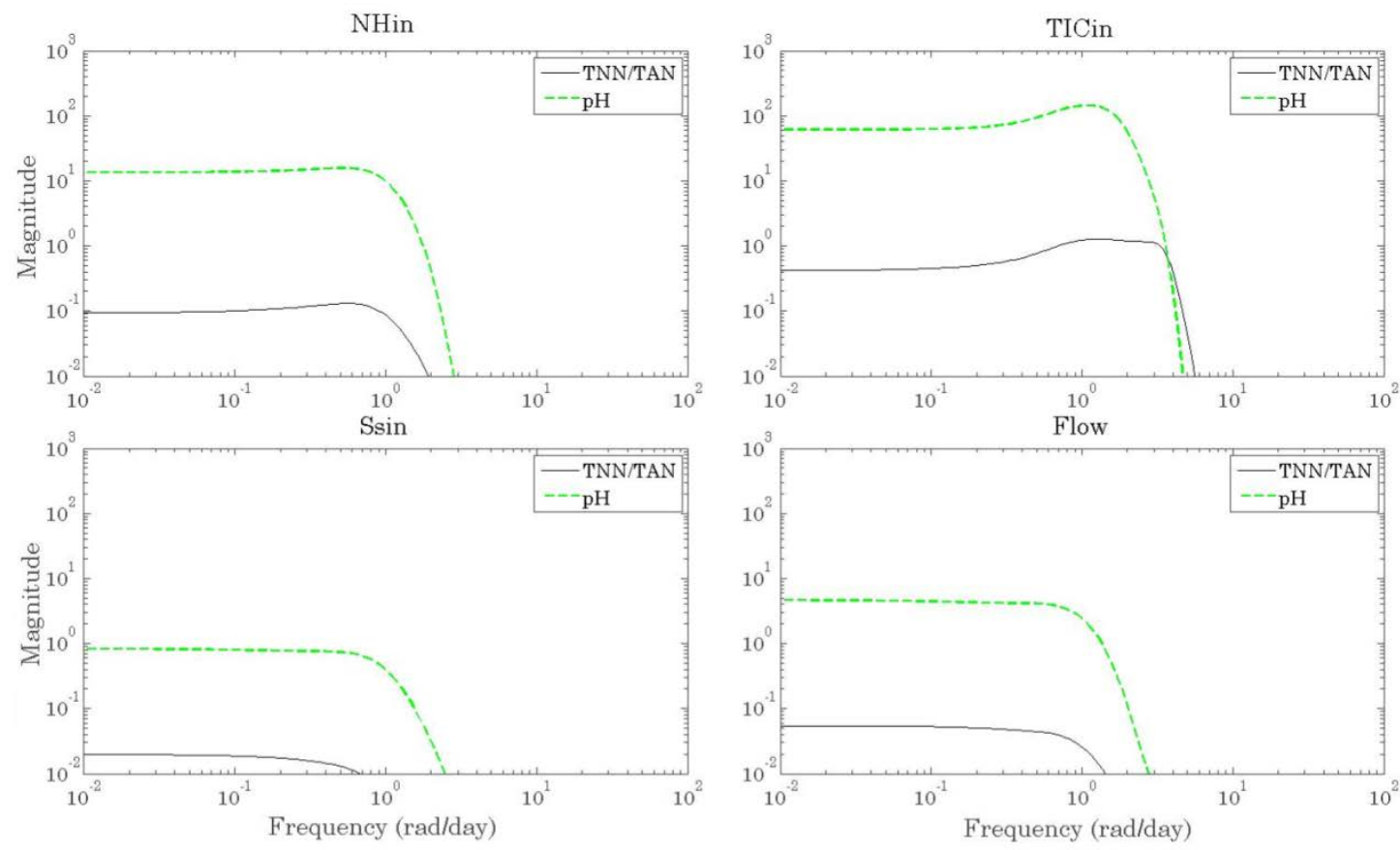

18 Figure S-7. Closed-loop disturbance plots for selected controlled variables TNN/TAN and pH. Green: variable controlled by $\mathrm{k}_{\mathrm{L} a}$; black: variable controlled by acid/base flow rate. 

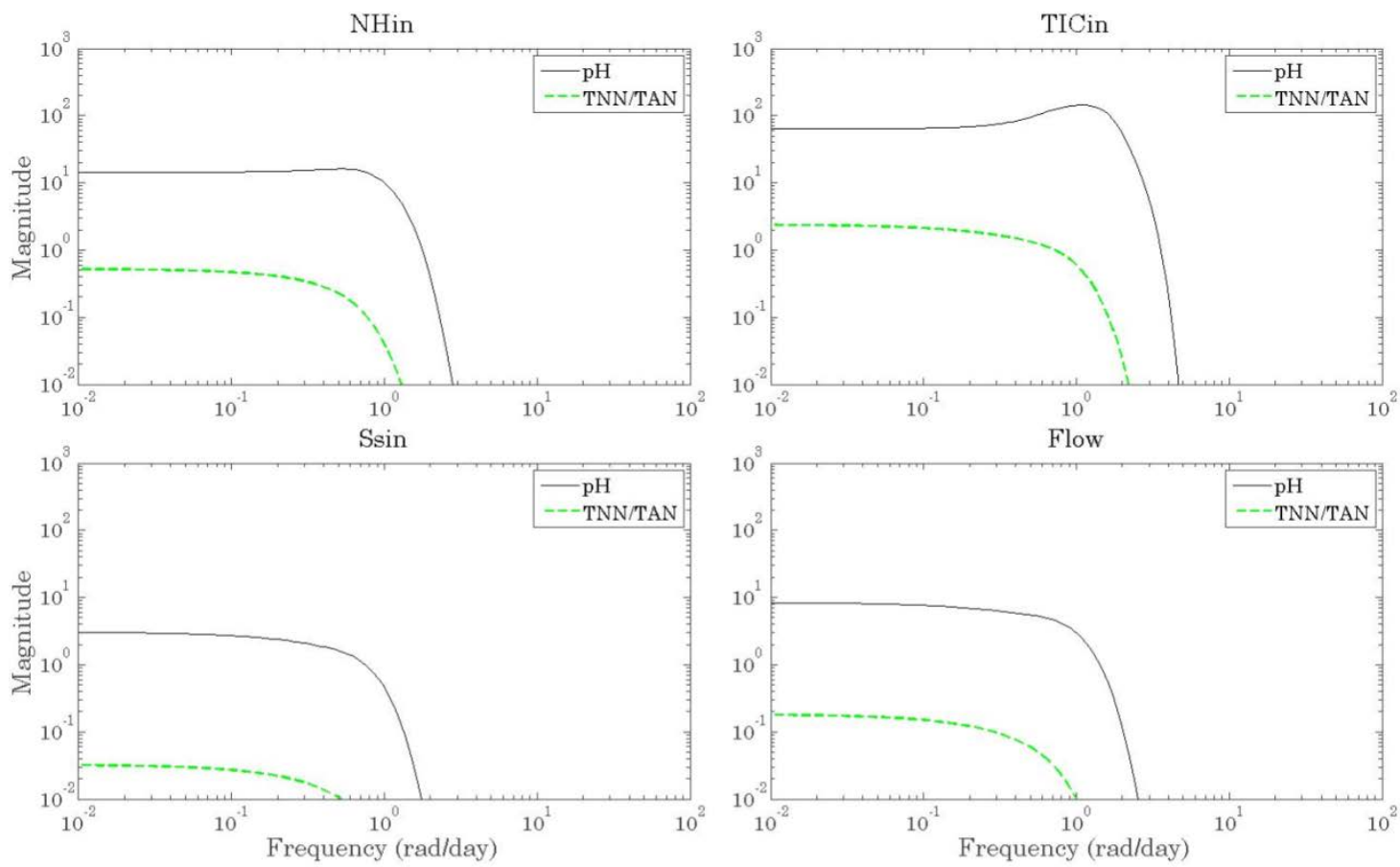

Figure S-8 Closed-loop disturbance plots for selected controlled variables TNN/TAN and TAN. Green: variable controlled by kLa; black: variable controlled by acid/base flow rate. (To be included in the supplementary information).

SI-4 Relative gain arrays:

Table S7 Relative gain array for dissolved oxygen (DO) and TAN.

\begin{tabular}{|l|l|l|l|}
\cline { 3 - 4 } \multicolumn{2}{c|}{} & Manipulated variables \\
\hline \multirow{3}{*}{ Controlled variables } & & Fbase & k \\
\cline { 2 - 4 } & DO & -0.1014 & 1.1014 \\
\cline { 2 - 4 } & TAN & 1.1014 & -0.1014 \\
\hline
\end{tabular}

Table S8 Relative gain array for TNN/TAN and TAN.

\begin{tabular}{|l|l|l|l|}
\cline { 3 - 4 } \multicolumn{2}{c|}{} & Manipulated variables \\
\hline \multirow{3}{*}{ Controlled variables } & & Fbase & $k_{\llcorner} a$ \\
\cline { 2 - 4 } & TNN/TAN & 0.7531 & 0.2469 \\
\cline { 2 - 4 } & TAN & 0.2469 & 0.7531 \\
\hline
\end{tabular}

31

Table 4. Relative gain array for TNN/TAN and pH. 
33

40

SI-5 Process flow diagrams:

Manipulated variables

\begin{tabular}{|l|l|l|l|}
\hline \multirow{3}{*}{ Controlled variables } & & Fbase & $\mathrm{k}_{\mathrm{L}} \mathrm{a}$ \\
\cline { 2 - 4 } & TNN/TAN & 0.823 & 0.1377 \\
\cline { 2 - 4 } & $\mathrm{pH}$ & 0.1377 & 0.823 \\
\hline
\end{tabular}

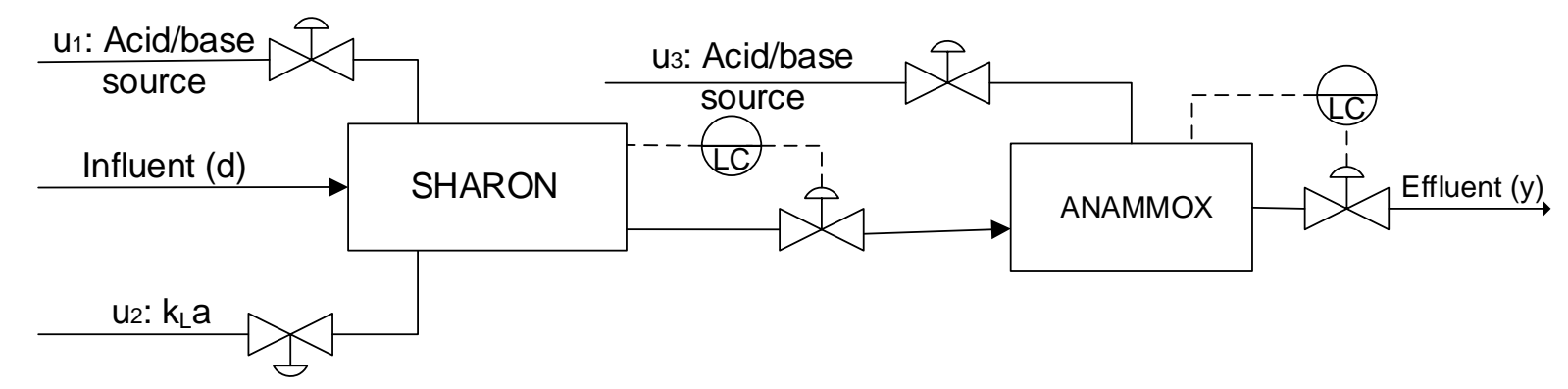

Figure S-9 Diagram of the SHARON-Anammox sequence. Actuators available for control design (u): acid/base flow rates into the reactors and $k_{\llcorner}$a. Disturbances in the influent (d): Ammonia nitrogen load, total inorganic carbon load, readily biodegradable COD, inflow rate. Potential controlled variables (y): dissolved oxygen, $\mathrm{pH}, \mathrm{TAN}, \mathrm{TNN}, \mathrm{TNN} / \mathrm{TAN}$.

$\mathrm{DOC}=\mathrm{DO}$ Controller

$\mathrm{pHC}=\mathrm{pH}$ Controller

LC = Level Controller

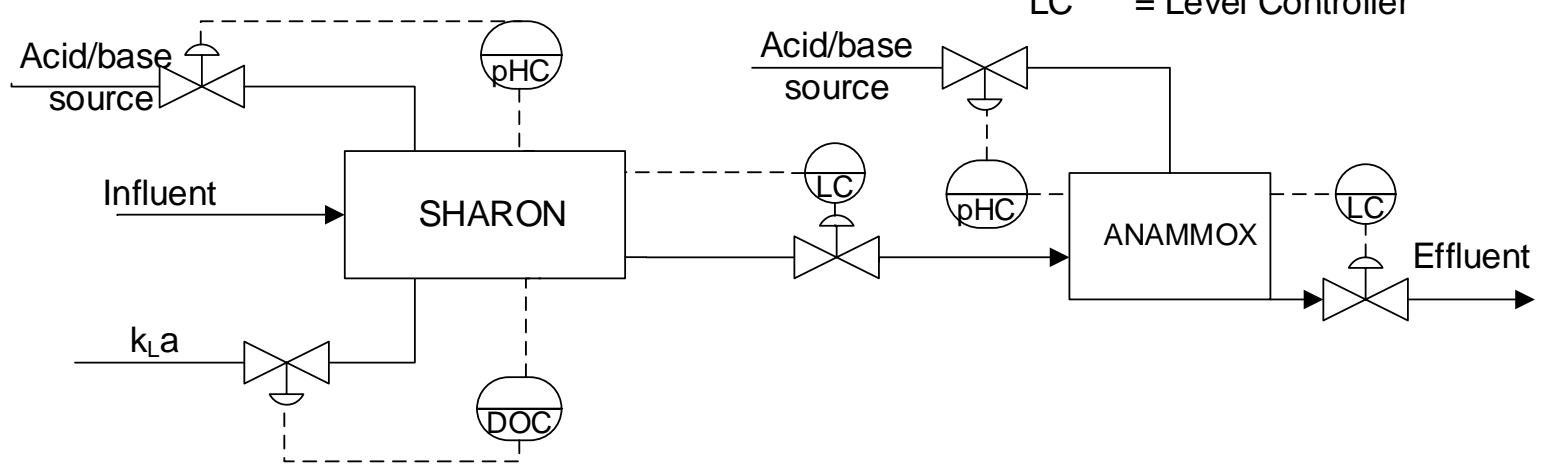

Figure S-10 Regulatory control layer for the SHARON-Anammox reactor sequence. 
[1] A.K. Vangsgaard, M. Mauricio-Iglesias, K.V. Gernaey, B.F. Smets, G. Sin, Sensitivity analysis of autotrophic $\mathrm{N}$ removal by a granule based bioreactor: Influence of mass transfer versus microbial kinetics. Bioresource Technology, 123 (2012) 230-241.

[2] X.D. Hao, J.J. Heijnen, M.C.M. Van Loosdrecht, Model-based evaluation of temperature and inflow variations on a partial nitrification-ANAMMOX biofilm process. Water Research, 36 (19) (2002), 4839-4849. 
[3] U. Wiesmann, 1994. Biological nitrogen removal from wastewater. Advances in Biochemical Engineering and Biotechnology. 51, ed. by A. Fiechter, Springer-Verlag Berlin, New York, 113-154.

[4] S. Van Hulle 2005. Modelling, simulation and optimization of autotrophic nitrogen removal processes. PhD dissertation, Ghent University, Ghent.

[5] M. Strous, J.G. Kuenen, M.S.M. Jetten, Key physiology of anaerobic ammonium oxidation. Applied and Environmental Microbiology, 65 (1999), 3248-3250.

[6] M. Strous, J.J. Heijnen, J.G. Kuenen, M.S.M. Jetten, The sequencing batch reactor as a powerful tool for the study of slowly growing anaerobic ammonium-oxidizing microorganisms. Applied Microbiology and Biotechnology, 50 (1998), 589-596.

[7] M. Henze, W. Gujer, T. Mino, M.C.M. van Loosdrecht, 2000. Activated sludge models ASM1, ASM2, ASM2D and ASM3, Scientific Technical Report No.9, IWA Publishing.

[8] J. Villadsen, J. Nielsen, G. Lidén, 2011. Bioreaction Engineering Principles. Springer US, Boston, MA.

[9] G. Sin, P.A. Vanrolleghem, Extensions to modeling aerobic carbon degradation using combined respirometric-titrimetric measurements in view of activated sludge model calibration. Water Research, 41 (2007), 3345-3358.

[10] A.K.Vangsgaard, M. Mauricio-Iglesias, B. Valverde-Pérez, K.V. Gernaey, G. Sin, pH variation and influence in an autotrophic nitrogen removing biofilm system using an efficient numerical solution strategy. Water Science and Technology, 67(11) (2013) 2605-2615.

[11] S. Van Hulle, E.I.P. Volcke, J. López Teruel, B. Donckels, M.C.M. Van Loosdrecht, P.A. Vanrolleghem, Influence of temperature and $\mathrm{pH}$ on the process kinetics of the SHARON nitritation process. Journal of Chemical Technology and Biotechnology, 82 (2007) 471-480.

[12] Y. Li, Z. Huang, W. Ruan, H. Ren, M. Zhao, ANAMMOX performance, granulation and microbial response under COD disturbance. Journal of Chemical Technology and Biotechnology, 90, 139-148. 